\title{
Evaluation of ground-based black carbon measurements by filter-based photometers at two Arctic sites
}

DOI:

10.1002/2016JD025843

\section{Document Version}

Final published version

Link to publication record in Manchester Research Explorer

\section{Citation for published version (APA):}

Sinha, P. R., Kondo, Y., Koike, M., Ogren, J. A., Jefferson, A., Barrett, T. E., Sheesley, R. J., Ohata, S., Moteki, N., Coe, H., Liu, D., Irwin, M., Tunved, P., Quinn, P. K., \& Zhao, Y. (2017). Evaluation of ground-based black carbon measurements by filter-based photometers at two Arctic sites. Journal of Geophysical Research: Atmospheres . https://doi.org/10.1002/2016JD025843

Published in:

Journal of Geophysical Research: Atmospheres

\section{Citing this paper}

Please note that where the full-text provided on Manchester Research Explorer is the Author Accepted Manuscript or Proof version this may differ from the final Published version. If citing, it is advised that you check and use the publisher's definitive version.

\section{General rights}

Copyright and moral rights for the publications made accessible in the Research Explorer are retained by the authors and/or other copyright owners and it is a condition of accessing publications that users recognise and abide by the legal requirements associated with these rights.

\section{Takedown policy}

If you believe that this document breaches copyright please refer to the University of Manchester's Takedown Procedures [http://man.ac.uk/04Y6Bo] or contact uml.scholarlycommunications@manchester.ac.uk providing relevant details, so we can investigate your claim.

\section{OPEN ACCESS}




\section{Journal of Geophysical Research: Atmospheres}

\section{RESEARCH ARTICLE \\ 10.1002/2016JD025843 \\ Evaluation of ground-based black carbon measurements by filter-based photometers at two Arctic sites}

\section{Key Points:}

- We evaluated the accuracy of black carbon (BC) measurements at Barrow, Alaska, and Ny-Ålesund, Spitsbergen, in the Arctic

- At Barrow, seasonally averaged BC mass concentrations decreased in winter and summer at a rate of $0.55 \pm 0.30 \mathrm{ng} \mathrm{m}^{-3} \mathrm{yr}^{-1}$ during 1998-2015

- We established seasonal variations of $\mathrm{BC}$ at the two sites and evaluated the causes of the inconsistency of the previously reported data

\section{Correspondence to:}

Y. Kondo,

kondo.yutaka@nipr.ac.jp

\section{Citation:}

Sinha, P. R., et al. (2017), Evaluation of ground-based black carbon measurements by filter-based photometers at two Arctic sites, J. Geophys. Res. Atmos., 122, 3544-3572, doi:10.1002/ 2016JD025843.

Received 26 AUG 2016 Accepted 3 MAR 2017 Accepted article online 9 MAR 2017 Published online 29 MAR 2017

\author{
P. R. Sinha ${ }^{1,2}$, Y. Kondo 3 (D) M. Koike' ${ }^{1}$, J. A. Ogren ${ }^{4,5}$ (D, A. Jefferson ${ }^{5}$ (D) T. E. Barrett ${ }^{6}$, \\ R. J. Sheesley ${ }^{6,7}$ D, S. Ohata ${ }^{1}$, N. Moteki ${ }^{1}$, H. Coe ${ }^{8}$, D. Liu ${ }^{8}$ (D) M. Irwin ${ }^{9}$, P. Tunved ${ }^{10}$, \\ P. K. Quinn ${ }^{11}$ iD, and Y. Zhao ${ }^{12}$
}

${ }^{1}$ Department of Earth and Planetary Science, Graduate School of Science, University of Tokyo, Tokyo, Japan, ${ }^{2}$ Balloon Facility, Tata Institute of Fundamental Research, Hyderabad, India, ${ }^{3}$ National Institute of Polar Research, Tachikawa, Japan, ${ }^{4}$ NOAA/ESRL Global Monitoring Division, Boulder, Colorado, USA, ${ }^{5}$ Cooperative Institute for Research in Environmental Sciences, University of Colorado Boulder, Boulder, Colorado, USA, ${ }^{6}$ The Institute of Ecological, Earth, and Environmental Sciences, Baylor University, Waco, Texas, USA, ${ }^{7}$ Department of Environmental Science, Baylor University, Waco, Texas, USA, ${ }^{8}$ Centre for Atmospheric Science, School of Earth, Atmospheric and Environmental Sciences, University of Manchester, Manchester, UK, ${ }^{9}$ Cambustion Ltd, Cambridge, UK, ${ }^{10}$ Department of Environmental Science and Analytical Chemistry, Stockholm University, Stockholm, Sweden, ${ }^{11}$ NOAA PMEL, Seattle, Washington, USA, ${ }^{12}$ Air Quality Research Center, University of California, Davis, California, USA

Abstract Long-term measurements of the light absorption coefficient $\left(b_{\mathrm{abs}}\right)$ obtained with a particle soot absorption photometer (PSAP), $b_{\text {abs }}$ (PSAP), have been previously reported for Barrow, Alaska, and Ny-Ålesund, Spitsbergen, in the Arctic. However, the effects on $b_{\mathrm{abs}}$ of other aerosol chemical species coexisting with black carbon $(\mathrm{BC})$ have not been critically evaluated. Furthermore, different mass absorption cross section (MAC) values have been used to convert $b_{\mathrm{abs}}$ to $\mathrm{BC}$ mass concentration $\left(M_{\mathrm{BC}}=b_{\mathrm{abs}} / \mathrm{MAC}\right)$. We used a continuous soot monitoring system (COSMOS), which uses a heated inlet to remove volatile aerosol compounds, to measure $b_{\mathrm{abs}}\left(b_{\mathrm{abs}}(\mathrm{COSMOS})\right)$ at these sites during 2012-2015. Field measurements and laboratory experiments have suggested that $b_{\text {abs }}$ (COSMOS) is affected by about $9 \%$ on average by sea-salt aerosols. $M_{\mathrm{BC}}$ values derived by $\operatorname{COSMOS}\left(M_{\mathrm{BC}}(\mathrm{COSMOS})\right)$ using a MAC value obtained by our previous studies agreed to within $9 \%$ with elemental carbon concentrations at Barrow measured over 11 months. $b_{\text {abs }}$ (PSAP) was higher than $b_{\text {abs }}(C O S M O S)$, by $22 \%$ at Barrow $\left(\mathrm{PM}_{1}\right)$ and by $43 \%$ at Ny-Ålesund $\left(\mathrm{PM}_{10}\right)$, presumably due to the contribution of volatile aerosol species to $b_{\mathrm{abs}}$ (PSAP). Using $b_{\mathrm{abs}}$ (COSMOS) as a reference, we derived $M_{\mathrm{BC}}$ (PSAP) from $b_{\text {abs }}$ (PSAP) measured since 1998. We also established the seasonal variations of $M_{\mathrm{BC}}$ at these sites. Seasonally averaged $M_{\mathrm{BC}}$ (PSAP) decreased at a rate of about $0.55 \pm 0.30 \mathrm{ng} \mathrm{m}^{-3} \mathrm{yr}^{-1}$. We also compared $M_{\mathrm{BC}}$ (COSMOS) and scaled $M_{\mathrm{BC}}$ (PSAP) values with previously reported data and evaluated the degree of inconsistency in the previous data.

\section{Introduction}

Black carbon (BC) particles are emitted as a result of incomplete combustion of both natural and anthropogenic carbon-based fuels. BC particles influence the radiation budget of the Earth's atmosphere by strongly absorbing solar radiation [Bond et al., 2013; Kondo, 2015]. Warming is occurring in the Arctic at about twice the global average rate [Shindell and Faluvegi, 2009] owing to a combination of climate feedbacks, including radiation feedback [Sand et al., 2016]. Light-absorbing particles such as BC likely contribute to radiative forcing in the Arctic also by changing the albedo of snow through the deposition of BC [Bond et al., 2013; Flanner et al., 2007; Shindell and Faluvegi, 2009]. However, estimates by climate models of the effects of $B C$ on Arctic warming are still highly uncertain, in part because measurements of the spatiotemporal distribution of the mass concentration of $\mathrm{BC}\left(M_{\mathrm{BC}}\right)$ in the atmosphere are limited and not sufficiently accurate.

To better understand the distribution of $M_{\mathrm{BC}}$ and the processes controlling $M_{\mathrm{BC}}$ in the Arctic, both aircraft measurements [Kondo et al., 2011a; Liu et al., 2015; Matsui et al., 2011; McNaughton et al., 2011; Spackman et al., 2010; Warneke et al., 2009, 2010] and ground-based measurements [Bodhaine, 1995; Delene and Ogren, 2002; Eleftheriadis et al., 2009; Hirdman et al., 2010a; Sharma et al., 2013] have been conducted. We summarize the nomenclature of physical parameters related to absorption and scattering by aerosol particles and the mass concentration of BC particles derived by different instruments in Table 1. 
Table 1. Summary of the Variable Symbols and Acronyms Used in This Study Term Definition

$b_{\text {abs }}$

$b_{\text {sca }}$

$b_{\text {abs }}$ (COSMOS)

$b_{\mathrm{abs}}$ (PSAP)

MAC

$M \mathrm{BC}$

Aerosol light absorption coefficient, also denoted as $\sigma_{\mathrm{ap}}$ in the literature

Aerosol light-scattering coefficient, also denoted as $\sigma_{\mathrm{sp}}$ in the literature

$b_{\text {abs }}$ measured by a continuous soot monitoring system (COSMOS)

Mass absorption cross section

$M_{\mathrm{BC}}(\mathrm{COSMOS})$

Mass concentration of black carbon (BC). Used in a general sense, and not used when reporting or discussing measurements of the mass concentration of BC

$M_{\mathrm{BC}}$ (PSAP)

Mass concentratior
$8.73 \mathrm{~m}^{2} \mathrm{~g}^{-1}$

$M_{\mathrm{BC}^{*}}{ }^{*}\left(\mathrm{PSAP} \mathrm{PM}_{1}\right)$
$M_{\mathrm{BC}}\left(\mathrm{PSAP}_{10} \mathrm{PM}_{10}\right)$
$M_{\mathrm{BC}}$ (aethalometer)
$M_{\mathrm{BC}}(\mathrm{SP} 2)$
$\mathrm{M}_{\mathrm{EC}}$

Mass concentration of black carbon derived from $b_{\text {abs }}$ (PSAP) by using a MAC value of $10.6 \mathrm{~m}^{2} \mathrm{~g}^{-1}$ at Barrow and $12.5 \mathrm{~m}^{2} \mathrm{~g}^{-1}$ at NyÅlesund, as derived herein such that the average $M_{\mathrm{BC}}$ (PSAP) values agree with $M_{\mathrm{BC}}$ (COSMOS) values. Termed equivalent black carbon (EBC) by Petzold et al. [2013]

$M_{\mathrm{BC}}$ (PSAP) for $\mathrm{PM}_{1}$ derived by Hirdman et al. [2010a, 2010b] by using a MAC of $10 \mathrm{~m}^{2} \mathrm{~g}^{-1}$

$M_{\mathrm{BC}}$ (PSAP) for $\mathrm{PM}_{10}$ derived by Hirdman et al. [2010a, 2010b] by using a MAC of $10 \mathrm{~m}^{2} \mathrm{~g}^{-1}$

$M_{\mathrm{BC}}$ derived from measurements of $b_{\mathrm{abs}}$ with an aethelometer by Sharma et al. [2013]

Mass concentration of refractory black carbon ( $\mathrm{rBC}$ ) derived from measurements with a single particle soot photometer (SP2)

Mass concentration of elemental carbon (EC) derived from thermo-optical transmittance (TOT) measurements of evolved carbon from filter samples

Detailed studies of emissions of BC from different sources (e.g., Asia, Europe, and North America) and its subsequent transport in the planetary boundary layer and free troposphere have been made by using aircraft measurements [Brock et al., 2011; Kondo et al., 2011a; Liu et al., 2015; Sahu et al., 2012; Spackman et al., 2010; Warneke et al., 2009, 2010]. These studies used a single particle soot photometer (SP2) and obtained accurate measurements of BC size distributions [e.g., Schwarz et al., 2006; Moteki and Kondo, 2008]. However, aircraft measurements are limited both spatially and temporally.

To date, most autonomous and continuous measurements of $M_{\mathrm{BC}}$ in the Arctic region have been made by a filter-based optical technique, mainly with a particle soot absorption photometer (PSAP; Radiance Research, Seattle, WA) or an aethalometer (Magee Scientific, Berkeley, CA, USA) [Bodhaine, 1995; Delene and Ogren, 2002; Eleftheriadis et al., 2009; Sharma et al., 2013]. However, these studies did not perform detailed error analyses, so the accuracy of the $M_{\mathrm{BC}}$ values derived from those measurements is uncertain.

Measurements obtained by filter-based absorption techniques need to be corrected for the effects of coexisting non-BC aerosol particles in the filter medium because ambient aerosols comprise a complex mixture of light-absorbing and nonabsorbing particles which optically interact [Bond et al., 1999, 2013]. We have deployed a continuous soot monitoring system called continuous soot monitoring system (COSMOS) (Kanomax, Osaka, Japan) [Miyazaki et al., 2008; Kondo et al., 2009, 2011b], which is a filter-based instrument equipped with an inlet heated at $300^{\circ} \mathrm{C}$ to remove nonrefractory components from the aerosol phase.

However, light transmission through the filter matrix is reduced not only due to refractory absorbing particles but also due to the presence of embedded light-scattering particles that do not evaporate during sampling through the heated inlet. As a result, $M_{\mathrm{BC}}$ determined by COSMOS ( $M_{\mathrm{BC}}$ (COSMOS)) may be overestimated, though Verma et al. [2011] found this effect to be small in Asia. Near the surface in the Arctic, however, $M_{\mathrm{BC}}$ is often lower by an order of magnitude than it is in midlatitudes [e.g., Liu et al., 2015; Spackman et al., 2010]. Therefore, nonvolatile aerosol components such as sea salt and mineral dust particles may substantially interfere with the $M_{\mathrm{BC}}$ (COSMOS) measurements, depending on their concentrations relative to those of $\mathrm{BC}$. Thus, there is a strong need to evaluate the uncertainties of $M_{\mathrm{BC}}$ (COSMOS), especially in remote regions such as the Arctic.

For this purpose, we conducted laboratory experiments to estimate how the presence of sea-salt particles affected $M_{\mathrm{BC}}$ (COSMOS). For overall evaluation of the accuracy of $M_{\mathrm{BC}}$ (COSMOS), we compared $M_{\mathrm{BC}}$ (COSMOS) with measurements of the mass concentration of elemental carbon (EC) $\left(M_{\mathrm{EC}}\right)$ made by the thermal-optical transmittance (TOT) technique at Barrow. We also compared $M_{\mathrm{BC}}$ (COSMOS) with $M_{\mathrm{BC}}$ measured near Ny-Ålesund by an SP2 onboard aircraft, although the available aircraft data are limited. We used the results of these comparisons to investigate the correlation of the $M_{\mathrm{BC}}$ (COSMOS) values with absorption coefficients measured by a PSAP $\left(b_{\text {abs }}\left(\right.\right.$ PSAP)) operated at Barrow, Alaska $\left(71.32^{\circ} \mathrm{N}, 156.61^{\circ} \mathrm{E}, 10 \mathrm{~m}\right.$ above 
sea level), by the National Oceanic and Atmospheric Administration (NOAA) Earth System Research Laboratory, Global Monitoring Division and at Zeppelin Station $\left(78.92^{\circ} \mathrm{N}, 11.93^{\circ} \mathrm{E}, 474 \mathrm{~m}\right.$ above sea level), Ny-Ålesund, Spitsbergen, operated by the Norwegian Polar Institute. We then scaled $b_{\text {abs }}$ (PSAP) measured at Barrow and Ny-Ålesund by comparing them with $M_{\mathrm{BC}}$ (COSMOS) based on high correlations between PSAP and COSMOS measurements. Finally, we used the scaled PSAP measurements to derive the long-term variations of $M_{\mathrm{BC}}$ (PSAP) at these sites.

\section{Absorption Coefficients and $M_{\mathrm{BC}}$ Obtained by PSAP and COSMOS}

The principles of operation of PSAP and COSMOS are identical; the attenuation of light at a given wavelength $\lambda, b_{0}(\lambda)$, in a filter-based absorption photometer, is determined by the following equation:

$$
b_{0}(\lambda)=\frac{A}{V_{a}} \ln \left[\frac{I_{t-\Delta t}}{I_{t}}\right],
$$

where $A$ is the area of the sample spot, $V_{a}$ is the air sample volume during a given time period between $(t-\Delta t)$ and $t$, and $l_{t-\Delta t}$ and $l_{t}$ are the average transmittances at $(t-\Delta t)$ and $t$, respectively [Bond et al., 1999].

In the case of a PSAP, absorption coefficients of aerosol particles collected on filters $\left(b_{\mathrm{abs}}\right)$ are derived from the measured attenuation $b_{0}$. Because the $b_{0}$ values measured by this instrument are influenced by light scattering by aerosols, these contributions are corrected by applying the empirical relation of Bond et al. [1999]:

$$
b_{\mathrm{abs}}(\mathrm{PSAP})=f_{\mathrm{fil}} b_{0}-f_{\mathrm{sca}} b_{\mathrm{sca}}
$$

where the second term on the right-hand side, $f_{\text {sca }} b_{\text {sca, }}$ represents a correction for light scattering by aerosol particles collected on filters. $b_{\text {sca }}$ is obtained by independent measurements, such as with a nephelometer. For PSAPs, $f_{\text {sca }}$ has been estimated to be $0.016 \pm 0.016$ [Bond et al., 1999]. In equation (2), $f_{\text {fil }}$ represents the increase in absorption by multiple scattering in the filter medium. In this study, the following equation, which was derived by using polydisperse nigrosine particles, is used for $f_{\text {fil }}$ [Bond et al., 1999]:

$$
f_{\text {fil }}(\operatorname{Tr})=\frac{1}{[1.0796 \operatorname{Tr}+0.71] B} \text { for } \operatorname{Tr} \geq 0.7
$$

where $\operatorname{Tr}\left(=I_{t} / I_{t=0}\right)$ is the filter transmission and $B=1.397$ is a scaling factor [Bond et al., 1999; Ogren, 2010]. Consequently, non-BC light-scattering particles (LSPs) can affect the estimate of $b_{\text {abs }}$ of BC in PSAP measurements, and the error associated with the correction for non-BC LSPs can be large, depending on the relative magnitudes of the two terms on the right-hand side of equation (2) [Bond et al., 1999].

For COSMOS, $b_{\text {sca }}$ is very close to zero for most aerosols, owing to the use of the heated inlet to remove volatile non-BC species [Kondo et al., 2011b]. In fact, the contribution of the $f_{\text {sca }} b_{\text {sca }}$ term of equation (2) to $b_{\text {abs }}$ (COSMOS) values has been estimated to be about $2 \%$ at midlatitudes [Kondo, 2015]. Hence, we used the following equation for COSMOS:

$$
b_{\mathrm{abs}}(\operatorname{COSMOS})=f_{\mathrm{fil}} b_{0}
$$

Equation (3) was used to account for the effect of multiple scattering for COSMOS. As a result of the removal of volatile non-BC species, errors associated with non-BC LSPs are small and COSMOS measures $b_{\text {abs }}$ of bare $\mathrm{BC}$ particles (core BC particles) accurately when all scattering particles are volatile. In contrast, a PSAP measures the light absorption of all particles, which is possibly enhanced by volatile coatings on the $B C$ particles (discussed below) and by scattering from nonrefractory particles within the PSAP filter matrix.

Changes in soot morphology during heating do not substantially affect $b_{\text {abs }}$ measurements by the COSMOS instrument. Laboratory experiments with an SP2 have shown that the change in the diameter of fullerene soot with initial diameters of 150 and $320 \mathrm{~nm}$ caused by heating the soot to $300^{\circ} \mathrm{C}$ is about $3 \%$ [Irwin et al., 2013]. Characteristics of fullerene soot were found to be representative of the ambient BC in Tokyo [Moteki and Kondo, 2010]. A PSAP measures the light absorption of all particles, which is possibly enhanced by coatings on $\mathrm{BC}$ particles, as discussed below. 
With both PSAPs and COSMOS, $M_{\mathrm{BC}}\left(\mathrm{g} \mathrm{m}^{-3}\right)$ can be estimated by dividing $b_{\mathrm{abs}}\left(\mathrm{m}^{-1}\right)$ by the mass absorption cross section of BC (MAC) $\left(\mathrm{m}^{2} \mathrm{~g}^{-1}\right)$, if the effects of LSPs are corrected for with sufficient accuracy and the effect of light-absorbing particles other than BC is neglected. Namely,

$$
M_{\mathrm{BC}}=b_{\mathrm{abs}} / \mathrm{MAC}
$$

Under the assumptions mentioned above, $b_{\text {abs }}$ (COSMOS) corresponds to the absorption of bare $\mathrm{BC}$ particles, so MAC (COSMOS) depends only (and slightly) on the size distribution of bare BC particles [Kondo et al., $2011 \mathrm{~b}$ ]. On the other hand, $b_{\mathrm{abs}}$ values obtained by PSAP potentially depend on the mixing state of BC and are also sensitive to absorption by non-BC species, such as brown carbon, which COSMOS does not sense. They also depend on the BC size distribution.

Light absorption by $\mathrm{BC}$ particles is enhanced by coatings of non-BC compounds, the so-called lens effect [e.g., Shiraiwa et al., 2010; Bond et al., 2013]. Therefore, the MAC (PSAP) value used to calculate $M_{B C}$ (PSAP) should be varied according to the mixing state of $B C$. In other words, the use of a constant MAC (PSAP) value to derive $M_{\mathrm{BC}}$ (PSAP) under varying atmospheric environmental conditions will introduce additional uncertainties into $M_{\mathrm{BC}}$ (PSAP) estimates.

To summarize, in principle, COSMOS measures $b_{\mathrm{abs}}$ of bare BC particles accurately, whereas PSAP measures $b_{\mathrm{abs}}$ of all particles, and the measured value is enhanced by coatings on $\mathrm{BC}$ particles. Furthermore, the MAC value used with COSMOS (MAC of bare BC particles) has less uncertainty than that used with PSAPs (MAC of various $\mathrm{BC}$ mixing states). Therefore, $M_{\mathrm{BC}}$ (COSMOS) is considered to be more accurate than $M_{\mathrm{BC}}$ (PSAP).

We note that $M_{\mathrm{BC}}$ (COSMOS) can be influenced not only by the uncertainty of MAC (COSMOS) due to variability of the BC size distribution but also by refractory LSPs (such as sea-salt and dust particles). These uncertainties are examined individually in the following sections. We then compare $M_{\mathrm{BC}}$ (COSMOS) values with $M_{\mathrm{BC}}$ (PSAP) values and discuss the overall uncertainty of $M_{\mathrm{BC}}$ measurement in detail.

\section{Measurements of $b_{\text {abs }}$ by COSMOS and PSAP in the Arctic}

COSMOS measures $b_{\text {abs }}$ of BC particles deposited on quartz filters (Pallflex, E70-2075W) at a wavelength $(\lambda)$ of $565 \mathrm{~nm}$. In Asia, the uncertainty of $b_{\text {abs }}$ (COSMOS) has been found to be better than $10 \%$ for an integration time of $1 \mathrm{~h}$ [Kondo et al., 2011b]. COSMOS was operated at Barrow from August 2012 to December 2015 and at Ny-Ålesund from April 2012 to December 2015 (Figure 1). The measurements of $b_{\text {abs }}$ by $\operatorname{COSMOS}\left(b_{\text {abs }}\right.$ (COSMOS)) and the derived $M_{\mathrm{BC}}$ (COSMOS) values were made by using a $\mathrm{PM}_{1}$ impactor inlet (i.e., with a size cutoff at an aerodynamic diameter $D_{p}$ of about $1 \mu \mathrm{m}$ ). COSMOS aspirates ambient air at a flow rate of $0.7 \mathrm{~L} \mathrm{~min}^{-1}$ at standard temperature and pressure (STP: $273.15 \mathrm{~K}, 1013 \mathrm{hPa}$ ). The time resolution of the measurement was maintained at $1 \mathrm{~min}$.

Kondo et al. [2011b] and Miyakawa et al. [2016] showed that the accuracy of $M_{\mathrm{BC}}$ (COSMOS) measurements is approximately $10 \%$ through extensive comparisons with $M_{\mathrm{BC}}$ measurements made by SP2 and EC measurements made by the TOT technique at several sites in Asia. They demonstrated that SP2, TOT (EC), and COSMOS measurements are consistent in the Asian region. By this comparison, MAC was determined to be about $10.0 \mathrm{~m}^{2} \mathrm{~g}^{-1}$ by using $B=1.22$ in equation (3). In the present study, we used $B=1.397$ for the comparison of $b_{\mathrm{abs}}$ (COSMOS) with $b_{\mathrm{abs}}$ (PSAP). With a $B$ value of 1.397, MAC (COSMOS) must be $10.0 \times(1.22 / 1.397)=8.73 \mathrm{~m}^{2} \mathrm{~g}^{-1}$. Different $(B, M A C)$ combinations, for example, $\left(1.22,10.0 \mathrm{~m}^{2} \mathrm{~g}^{-1}\right)$ and $\left(1.397,8.73 \mathrm{~m}^{2} \mathrm{~g}^{-1}\right)$, result in an identical $M_{\mathrm{BC}}$ (COSMOS) value.

The $M_{\mathrm{BC}}$ (COSMOS)/ $M_{\mathrm{BC}}$ (SP2) ratio was observed to decrease by about $7 \%$ with an increase in the mass median diameter (MMD) of $50 \mathrm{~nm}$ (from 130 to $180 \mathrm{~nm}$ ) in Tokyo, possibly owing to the size dependence between MAC (COSMOS) and $f_{\text {fil }}$ [Kondo et al., 2011b; Kondo, 2015]. In Tokyo, the mean MMD was $146 \pm 12 \mathrm{~nm}$, with a mean geometrical standard deviation $\left(\sigma_{\mathrm{gm}}\right)$ of $1.82 \pm 0.14$. Considering the variability of the observed size distribution in Asia and the Arctic (MMD mostly up to about $200 \mathrm{~nm}$ ) [Kondo, 2015], we estimated the typical uncertainty in $M_{\mathrm{BC}}$ (COSMOS) in the Arctic associated with the variability in $\mathrm{BC}$ size distribution to be about $10 \% . M_{\mathrm{BC}}$ (PSAP) should also be influenced by this effect, although the degree of influence may be different owing to internal mixing of $B C$ particles. 


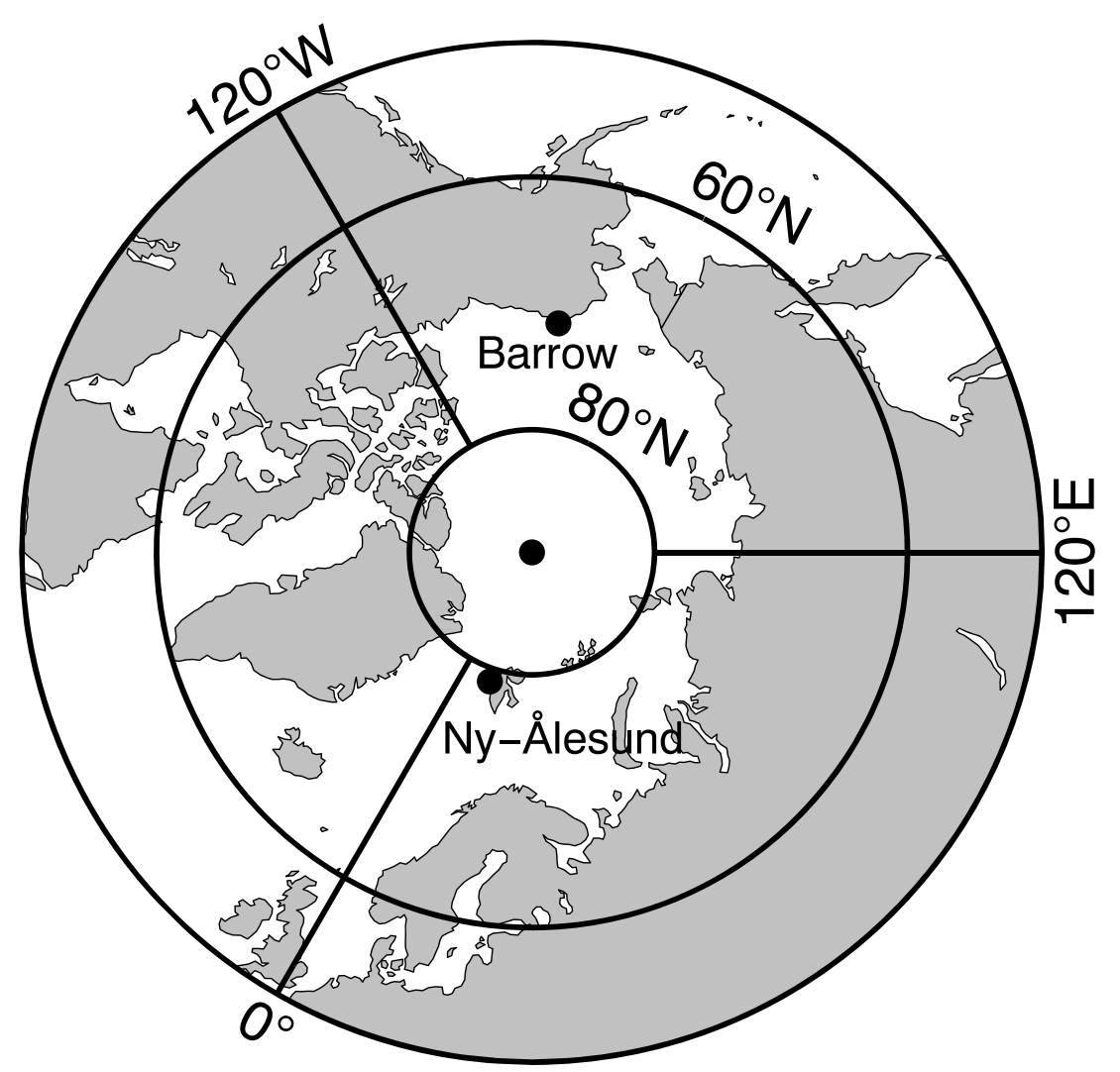

Figure 1. Map of the Arctic showing the locations of Barrow, Alaska, and Ny-Ålesund, Spitsbergen, where the BC measurements were made.

In this study, we also used $b_{\text {abs }}$ data obtained with a PSAP and a continuous light absorption photometer (CLAP) [Lack et al., 2014]. The CLAP is conceptually similar to PSAP but uses a solenoid valve to cycle through eight sample filter spots. Brief descriptions of the PSAP and CLAP measurements at Barrow and Ny-Ålesund are given here, and more details are provided in section A1. At these sites, all three instruments (PSAP, CLAP, and COSMOS) collected aerosol particles containing $B C$ on the same type of fiber filter (Pallflex, type E70-2075W). The PSAP and CLAP measured $b_{\mathrm{abs}}$ of aerosol particles collected on the filter at $\lambda=529 \mathrm{~nm}$ and $522 \mathrm{~nm}$, respectively, and both the PSAP and CLAP aspirated ambient air at a volumetric flow rate of $1 \mathrm{~L} \mathrm{~min}^{-1}$ (about $0.9 \mathrm{~L} \mathrm{~min}^{-1}$ at STP) using $\mathrm{PM}_{1}$ and $\mathrm{PM}_{10}\left(D_{p}<10 \mu \mathrm{m}\right)$ impactors alternately for $30 \mathrm{~min}$ of each hour. The values of $b_{\text {abs }}$ measured by PSAP $\left(b_{\text {abs }}\right.$ (PSAP)) and CLAP ( $b_{\text {abs }}($ CLAP)) at different wavelengths were adjusted to $550 \mathrm{~nm}$, to match the wavelength used for measurement of the scattering coefficient $\left(b_{\text {sca }}\right)$ by nephelometer (Model 3563, TSI Inc.). We used a conversion coefficient of about $0.96 \pm 0.01$, assuming a dependence of $b_{\mathrm{abs}}$ (PSAP) of $\lambda^{-1}$ or $\lambda^{-0.5}$ [Ogren, 2010]. Similarly, the coefficient of conversion from $\lambda=550 \mathrm{~nm}$ for PSAP to $\lambda=565 \mathrm{~nm}$ for COSMOS was $0.980 \pm 0.007$.

The uncertainty of the $1 \mathrm{~h}$ average $b_{\text {abs }}$ (PSAP) was estimated to be about $20 \%$ at midlatitudes $\left(35^{\circ} \mathrm{N}-45^{\circ} \mathrm{N}\right)$, considering instrumental noise and calibration following Bond et al. [1999], and unit-to-unit variability [Sherman et al., 2015]. In this study, we used CLAP data obtained at Barrow between August 2012 and December 2015. The daily mean $b_{\mathrm{abs}}$ (PSAP) and $b_{\mathrm{abs}}$ (CLAP) values agreed to within $2 \%$ during 20122015. Therefore, for simplicity, we consider the instruments to be equivalent and refer to CLAP data as PSAP data hereafter.

Similarly, at Ny-Ålesund, measurements of $b_{\text {abs }}$ at $532 \mathrm{~nm}$ were also carried out at about $10 \mathrm{~m}$ above the ground by using a custom-built PSAP [Krecl et al., 2007]. No cyclone or impactor was used, so there was no particle size cutoff for the PSAP data obtained at Ny-Ålesund. However, it is unlikely that a substantial number of particles with $D_{p}>10 \mu \mathrm{m}$ were included in the PSAP measurements, given the particle losses in the inlet 
system. Therefore, for simplicity, we refer to these data as $\mathrm{PM}_{10}$ data for comparison with the Barrow data. This simplification did not have a significant effect on the results of the present analysis.

The Arctic has basically two seasons. Therefore, for the analyses, the $M_{\mathrm{BC}}$ (COSMOS) and $M_{\mathrm{BC}}$ (PSAP) data were classified into winter (November-April) and summer (May-October) seasons.

\section{Effect of Sea-Salt Particles on $M_{\mathrm{BC}}$ Measured by COSMOS}

4.1. Laboratory Experiments

As discussed in section 3, in COSMOS measurements, light transmittance through a filter matrix is reduced by light scattering by refractory aerosol particles such as sea salt (predominantly $\mathrm{NaCl}$ ) and mineral dust. Sea-salt particles are reported to constitute about $20 \%$ of the mass concentration of aerosols with diameters less than $1 \mu \mathrm{m}$ at Barrow [Quinn et al., 2002].

To assess the interference from sea-salt particles on $M_{\mathrm{BC}}$ (COSMOS), we performed laboratory experiments, as shown schematically in Figure 2. The aim of the experiments was to estimate the decrease in transmittance per unit scattering coefficient or volume (mass) of sea-salt particles. The refractive indices of $\mathrm{NaCl}$ are 1.54 and 1.55 at $\lambda=589 \mathrm{~nm}$ and $565 \mathrm{~nm}$, respectively, whereas the refractive indices of polystyrene latex (PSL) are 1.59 and 1.60 at $\lambda=589 \mathrm{~nm}$ and $486 \mathrm{~nm}$, respectively. Given that $\mathrm{NaCl}$ constitutes the major fraction of sea-salt particles [Barrie and Barrie, 1990], it is likely that sea-salt particles and PSL have similar optical effects on $M_{\mathrm{BC}}$ (COSMOS). Thus, in our experiments, we used PSL, which does not evaporate at $300^{\circ} \mathrm{C}$, as a surrogate for sea-salt particles, which are not accurately sized by our calibration system because they are not spherical.

Water samples containing PSL particles were introduced by a peristaltic pump into a nebulizer at a constant flow rate (Figure 2a). The nebulizer then aerosolized PSL particles from the water suspension and passed them to a differential mobility analyzer (Model 3081, TSI Inc., MN, USA) for size segregation according to their mobility diameters. Monomodal PSL particles with diameters of $254 \mathrm{~nm}, 506 \mathrm{~nm}$, and $814 \mathrm{~nm}$ were then sampled by COSMOS and SP2. The light-scattering data from the SP2 were used to derive the number concentration of PSL particles from the light-scattering data.

The scattering coefficient $\left(\mathrm{Mm}^{-1}\right)$ of the PSL particles at $\lambda=565 \mathrm{~nm}\left(b_{\mathrm{sca}}(\mathrm{PSL})\right)$ was calculated from their number concentration as measured by the SP2 on the basis of Mie theory. The volume concentration $\left(V_{\mathrm{PSL}}, \mu \mathrm{m}^{3} \mathrm{~cm}^{-3}\right)$ of the extracted PSL particles was also calculated from their number concentration and known diameter. The measured transmittance change of COSMOS due to PSL particles deposited on the filter was converted to the apparent $\mathrm{BC}$ mass concentration, denoted as $\Delta M_{\mathrm{BC}}\left(\mu \mathrm{g} \mathrm{m}^{-3}\right)$.

$\Delta M_{\mathrm{BC}}$ correlated well with $b_{\mathrm{sca}}$ (PSL) (Figure 3). As expected, $\Delta M_{\mathrm{BC}}$ also correlated well with $V_{\mathrm{PSL}}$ (not shown). The $\Delta M_{\mathrm{BC}} / b_{\text {sca }}$ (PSL) ratios, which showed only small dependence on the PSL diameters, were found to be about $0.0021 \mu \mathrm{g} \mathrm{m}^{-3} / \mathrm{Mm}^{-1}$. The $\Delta M_{\mathrm{BC}} / V_{\mathrm{PSL}}$ ratios, which also showed little dependence on the PSL diameters, were found to be about $0.022 \mu \mathrm{g} \mathrm{m}^{-3} / 10^{-6} \mathrm{~cm}^{3} \mathrm{~m}^{-3}$. The observed size dependence on PSL diameter was significantly smaller than that calculated on the basis of Mie theory for airborne PSL particles [Moteki et al., 2010].

Considering these results, we used an average $\Delta M_{\mathrm{BC}} / b_{\text {sca }}(\mathrm{PSL})$ ratio of $0.0021 \mu \mathrm{g} \mathrm{m}^{-3} / \mathrm{Mm}^{-1}$ for the subsequent analysis as follows:

$$
\Delta M_{\mathrm{BC}}\left(\mu \mathrm{g} \mathrm{m}^{-3}\right)=0.0021\left[\mu \mathrm{g} \mathrm{m}^{-3} / \mathrm{Mm}^{-1}\right] \times b_{\mathrm{sca}}(\mathrm{PSL})\left[\mathrm{Mm}^{-1}\right] .
$$

Using this relationship, we also estimated $f_{\text {sca }}$ in equation (2) as $f_{\text {sca }}=0.0021\left(\mathrm{~g} \mathrm{~m}^{-3} / \mathrm{m}^{-1}\right) \times$ MAC (COSMOS) $\left(\mathrm{m}^{2} \mathrm{~g}^{-1}\right)=0.0021 \times 8.73=0.018$. This value is very similar to the value of 0.016 derived by Bond et al. [1999] by using polydisperse LSPs $\left(\left(\mathrm{NH}_{4}\right)_{2} \mathrm{SO}_{4}\right.$ and $\mathrm{NaCl}$ ) (section 2). This agreement indicates that equation (6) is consistent with their measurement of the effect of LSPs on $b_{\text {abs }}$ (PSAP).

To further ascertain whether the relationship represented by equation (6) is valid for ambient $M_{\mathrm{BC}}$ measurements, we conducted an additional experiment with a different configuration (Figure $2 \mathrm{~b}$ ). In the second experiment, ambient air containing BC particles was mixed with air containing PSL particles with a diameter of $506 \mathrm{~nm}$ and subsequently heated to $300^{\circ} \mathrm{C}$. An SP2 was used to measure the BC mass concentration and the PSL number concentration, and then we derived the scattering coefficient of PSL from these measurements. 
(a)

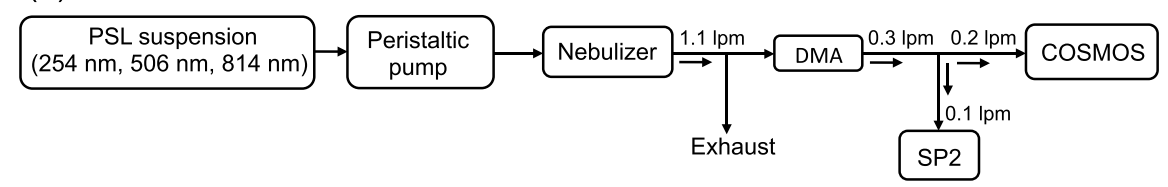

(b)

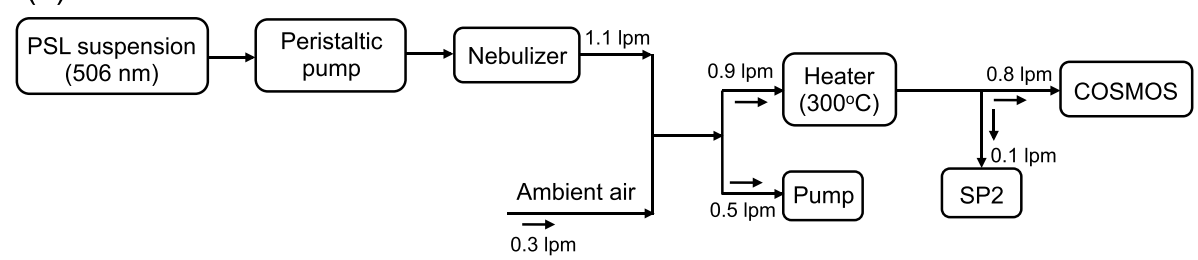

Figure 2. Experimental setup for the estimation of the decrease in transmittance per unit scattering coefficient or volume (mass) concentration of sea-salt particles in COSMOS $M_{\mathrm{BC}}$ measurements. (a) Water samples containing polystyrene latex (PSL) particles are introduced by a peristaltic pump into a nebulizer at a constant flow rate of $3.0 \times 10^{-6} \mathrm{Ls} \mathrm{s}^{-1}$. The nebulizer aerosolizes the PSL particles from a water suspension in dry air at a constant flow rate of $16 \mathrm{~cm}^{3} \mathrm{~s}^{-1}$ at STP $(273.15 \mathrm{~K}, 1013 \mathrm{hPa})$ and then passes the aerosol to a differential mobility analyzer (DMA) for mobility size segregation. Monomodal PSL particles with sizes of $254 \mathrm{~nm}, 506 \mathrm{~nm}$, and $814 \mathrm{~nm}$ are sampled by COSMOS and a single particle soot photometer (SP2). (b) Same as Figure 2a but PSL particles with a diameter of $506 \mathrm{~nm}$ are mixed with ambient air containing $\mathrm{BC}$ particles and the mixture is heated at $300^{\circ} \mathrm{C}$ before being sampled by COSMOS and SP2.

$\Delta M_{\mathrm{BC}} / b_{\text {sca }}$ (PSL) was approximately $0.0025 \mu \mathrm{g} \mathrm{m}^{-3} / \mathrm{Mm}^{-1}$ (correlations not shown). This value is similar to that obtained in the first experiment, indicating that interference from a mixture of $B C$ and sea-salt particles is very similar to interference from sea-salt particles alone. We used equation (6) to estimate the error due to sea-salt aerosol particles, as described in section 4.2.

\subsection{Error Estimation}

For the measurements of the sea-salt mass concentration $\left(M_{s-s}\right)$ at Barrow, ambient air samples were collected through an inlet mounted $10 \mathrm{~m}$ above the ground onto filters by using $\mathrm{PM}_{1}$ and $\mathrm{PM}_{10}$ impactors at 1 to 4 day intervals between October 1997 and December 2009. At Ny-Ålesund, air samples containing sea-salt particles

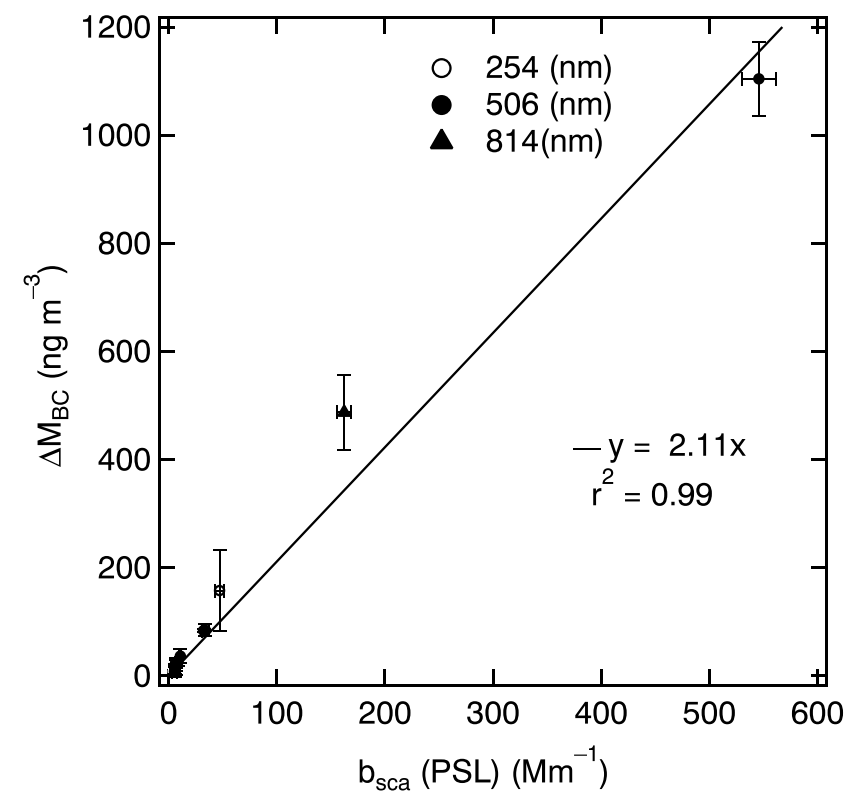

Figure 3. Relationship between the measured apparent $B C$ mass concentration $\left(\triangle M_{\mathrm{BC}}\right)$ and the scattering coefficient of PSL particles $\left(b_{\text {sca }}(P S L)\right)$ with diameters of $254 \mathrm{~nm}, 506 \mathrm{~nm}$, and $814 \mathrm{~nm}$, calculated from number concentrations measured by SP2. Note that the regression line fit was forced through origin (intercept $=0$ ). 

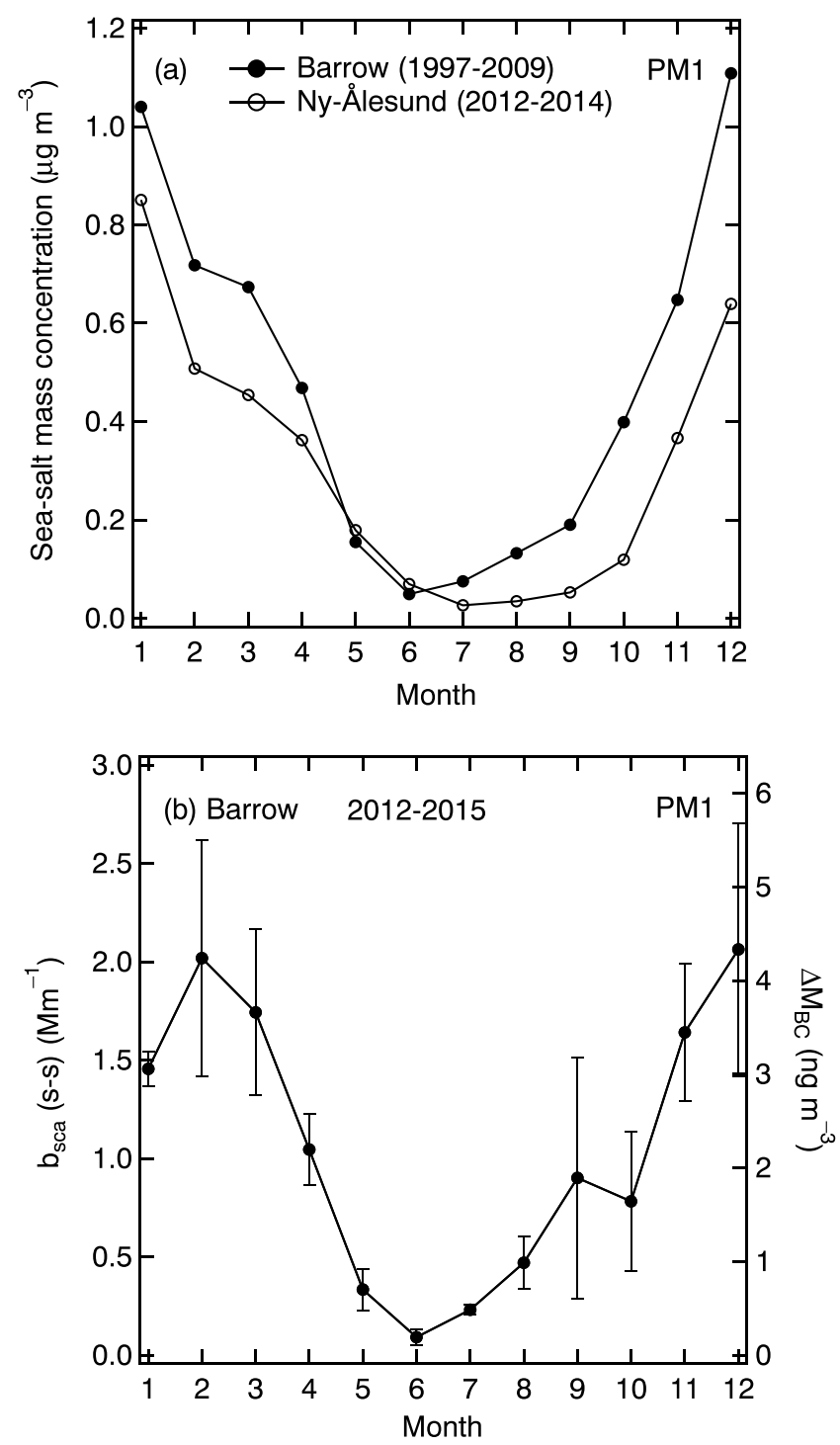

Figure 4. (a) Monthly mean mass concentrations of sea-salt particles at Barrow from October 1997 to December 2009 and at Ny-Ålesund from January 2012 to December 2014. (b) Monthly mean scattering coefficients of sea-salt particles $\left(b_{\text {sca }}(s-s)\right)$ and corresponding apparent $\mathrm{BC}$ mass concentrations $\left(\Delta M_{\mathrm{BC}}\right)$. The vertical bars represent the standard deviations $( \pm 1 \sigma)$ of the monthly mean values.

were collected daily from January 2012 to December 2014 without use of an impactor. For simplicity, we also designated these data as $\mathrm{PM}_{10}$. More detailed descriptions of the $M_{s-s}$ measurements are presented in section A2.

$M_{s-s}$ was calculated from measured $\mathrm{Na}^{+}$and $\mathrm{Cl}^{-}$with equation (7) [Holland, 1978].

$$
M_{s-s}\left(\mu \mathrm{g} \mathrm{m}^{-3}\right)=\mathrm{Cl}\left(\mu \mathrm{g} \mathrm{m}^{-3}\right)+\mathrm{Na}\left(\mu \mathrm{g} \mathrm{m}^{-3}\right) \times 1.47 .
$$

The factor 1.47 is the $\left(\mathrm{Na}+\mathrm{K}+\mathrm{Mg}+\mathrm{Ca}+\mathrm{SO}_{4}+\mathrm{HCO}_{3}\right) / \mathrm{Na}$ seawater ratio. The uncertainty arising from the use of equation (7) to estimate $M_{s-s}$ is described in section A2.

At both sites, $M_{s-s}$ showed similar and notable seasonal variations; values were about an order of magnitude higher in winter (about $1 \mu \mathrm{g} \mathrm{m}^{-3}$ ) than in summer (about $0.1 \mathrm{\mu g} \mathrm{m}^{-3}$ ) (Figure 4a). The seasonality and magnitude of $M_{s-s}$ at Barrow during 1997-2009 were very similar to those from October 1997 to December 2000 [Quinn et al., 2002]. This similarity suggests that the interannual variability of $M_{s-s}$ is relatively small. 
To estimate $\Delta M_{\mathrm{BC}}$ we first calculated the contribution of sea-salt aerosols to $b_{\text {sca }}$ for $\mathrm{PM}_{1}$ aerosols $\left(b_{\mathrm{sca}}\left(\mathrm{PM}_{1}\right)\right)$ measured at Barrow. For this calculation, we used mass concentrations and the scattering coefficient for $\mathrm{PM}_{1}$ aerosols measured at Barrow between 1997 and 2000 [Quinn et al., 2002]. The scattering coefficient of sea salt $\left(b_{\text {sca }}(s-s)\right)$ and $b_{\text {sca }}\left(\mathrm{PM}_{1}\right)$ can be calculated with equations (8a) and (8b). The monthly averaged values of these parameters, $\left(b_{\text {sca }}(s-s)\right)_{a v}$ and $\left(b_{\text {sca }}\left(\mathrm{PM}_{1}\right)\right)_{\mathrm{av}}$, were obtained from Quinn et al. [2002, Tables 2 and 4 ].

$$
\begin{gathered}
{\left[b_{\mathrm{sca}}(s-s)\right]_{\mathrm{av}}=\alpha_{\mathrm{s}-\mathrm{s}} \times\left[M_{s-s}\right]_{\mathrm{av}},} \\
{\left[b_{\mathrm{sca}}\left(\mathrm{PM}_{1}\right)\right]_{\mathrm{av}}=\alpha_{\mathrm{PM} 1} \times\left[M_{\mathrm{PM} 1}\right]_{\mathrm{av}},}
\end{gathered}
$$

where $\left[M_{s-s}\right]_{\mathrm{av}}$ and $\left[M_{\mathrm{PM} 1}\right]_{\mathrm{av}}$ are monthly averaged mass concentrations of sea-salt and $\mathrm{PM}_{1}$ aerosols, respectively, and $\alpha_{\mathrm{s}-\mathrm{s}}$ and $\alpha_{\mathrm{PM} 1}$ are the mass-scattering efficiencies $\left(\mathrm{m}^{2} \mathrm{~g}^{-1}\right)$ of sea-salt and total aerosols, respectively, for $\mathrm{PM}_{1}$.

The $\left[f_{s-s}\right]_{a v}=\left[b_{\text {sca }}(s-s)\right]_{a v} /\left[b_{s c a}\left(\mathrm{PM}_{1}\right)\right]_{\mathrm{av}}$ ratio ranged between 0.06 and 0.38 with an annual average of 0.24 . We used monthly averaged $b_{\text {sca }}\left(\mathrm{PM}_{1}\right)$ observed from August 2012 to December 2015 to estimate the monthly averaged $b_{\text {sca }}(s-s)$ by the following equation:

$$
b_{\mathrm{sca}}(s-s)=\left[f_{\mathrm{s}-s}\right]_{\mathrm{av}} \times b_{\mathrm{sca}}\left(\mathrm{PM}_{1}\right) .
$$

Finally, we calculated monthly mean $\Delta M_{\mathrm{BC}}$ by replacing $b_{\text {sca }}(\mathrm{PSL})$ in equation (6) with $b_{\mathrm{sca}}(\mathrm{s}-\mathrm{s})$ (Figure $\left.4 \mathrm{~b}\right)$. At Barrow, $\triangle M_{\mathrm{BC}}$ varied from about 0.19 to $4.3 \mathrm{ng} \mathrm{m}^{-3}$, with a mean value of about $2.2 \mathrm{ng} \mathrm{m}^{-3}$, which corresponds to about $9 \%$ of the annual mean $M_{\mathrm{BC}}$ (COSMOS).

Data similar to those used to derive $\Delta M_{\mathrm{BC}}$ at Barrow were not available at Ny-Ålesund. However, $\Delta M_{\mathrm{BC}}$ should be proportional to $M_{s-s}$ as shown by our laboratory experiments (section 4.1). At Ny-Ålesund, the $M_{s-s}$ values were about $30 \%$ lower than at Barrow (Figure $4 \mathrm{a}$ ) and the yearly average $\Delta M_{\mathrm{BC}}$ was estimated to be about $1.6 \mathrm{ng} \mathrm{m}^{-3}$.

In addition to sea-salt particles, mineral dust particles may contribute to $\Delta M_{\mathrm{BC}}$, although reported mass concentrations of dust particles in the Arctic are much less than those of sea-salt particles [Brock et al., 2011; Quinn et al., 2002]. The variability in BC size distribution may cause an additional uncertainty. Therefore, comparisons of $M_{\mathrm{BC}}$ (COSMOS) with the measurements of $M_{\mathrm{BC}}$ by other reliable techniques, such as the comparisons we did in Asia, are critically important for evaluating the overall accuracy of $M_{\mathrm{BC}}$ (COSMOS) in the Arctic.

\section{Comparisons of $M_{\mathrm{BC}}$ (COSMOS) With $M_{\mathrm{EC}}$ Measurements at Barrow and With $M_{\mathrm{BC}}$ (SP2) Measurements at Ny-Ålesund}

\subsection{Barrow}

To evaluate the overall accuracy of $M_{\mathrm{BC}}$ (COSMOS), we carried out a detailed intercomparison between $M_{\mathrm{BC}}$ (COSMOS) and the mass concentration of EC measured by the TOT technique at Barrow. For each $M_{\mathrm{EC}}$ measurement, air samples were collected at Barrow between August 2012 and June 2013 on a quartz fiber filter (Tissuquartz Filters 2500 QAT-UP; $20 \times 25 \mathrm{~cm}$ Pall Corporation) by using a Tisch high-volume sampler (TE-6070; Tisch Environmental Cleves, Ohio, USA) with a $\mathrm{PM}_{10}$ cutoff and a flow rate of about $1.2 \mathrm{~m}^{3} \mathrm{~min}^{-1}$ at $10 \mathrm{~m}$ above ground level. The particle-laden filters were analyzed with a TOT carbon analyzer (Sunset Laboratories, Tigard, OR, USA), and $M_{\mathrm{EC}}$ was quantified following the temperature protocol recommended by the National Institute for Occupational Safety and Health (NIOSH 5040) [Birch and Cary, 1996]. The M $M_{\mathrm{EC}}$ values are given in units of $\mathrm{ng} \mathrm{m}^{-3} \mathrm{STP}$. We estimated the uncertainty of $M_{\mathrm{EC}}$ associated with the uncertainty of the flow rate of the filter sampling to be about $10 \%$. We estimated the overall uncertainty of the $M_{\mathrm{EC}}$ measurement to be about $17 \%$ (excluding the uncertainty of the flow rate). More details of the EC measurements are given in section A3.

In Tokyo, the contributions of $\mathrm{BC}$ particles with diameters $\left(D_{\mathrm{BC}}\right)$ larger than $1 \mu \mathrm{m}$ to $M_{\mathrm{BC}}$ of particles with diameters less than about $4 \mu \mathrm{m}\left(\mathrm{PM}_{4}\right)$ were observed to be less than $10 \%$, based on SP2 measurements. At the remote site of Hedo $\left(26.9^{\circ} \mathrm{N}, 128.3^{\circ} \mathrm{E}\right)$ on Okinawa Island, Japan, the contribution was about $8 \%$ in spring 2016 


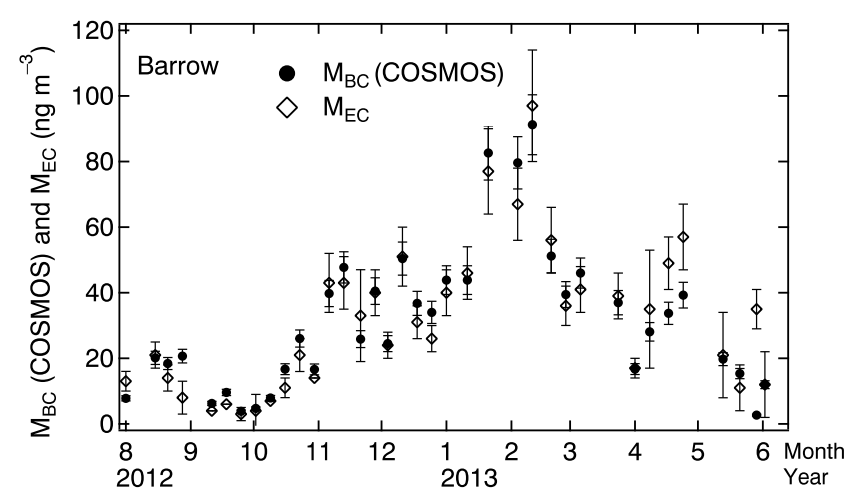

Figure 5. Time series of $M_{\mathrm{BC}}$ (COSMOS) and $M_{\mathrm{EC}}$ at Barrow between August 2012 and June 2013. The $M_{\mathrm{BC}}$ (COSMOS) data were averaged over the same period as the individual $M_{\mathrm{EC}}$ measurements.

(section A4, Figure A1a). BC particles become more active as cloud condensation nuclei as their diameters increase, and larger BC particles have been observed to be removed more efficiently by wet deposition than BC particles with smaller diameters [Ohata et al., 2016; Moteki et al., 2012; Kondo et al., 2016]. BC particles larger than $1 \mu \mathrm{m}$ should be scavenged more efficiently during long-range transport to the Arctic from lower latitudes. Therefore, it is unlikely that the contribution of $\mathrm{BC}$ particles larger than $1 \mu \mathrm{m}$ to $M_{\mathrm{BC}}$ (i.e., $\mathrm{PM}_{10}$ minus $\mathrm{PM}_{1}$ ) exceeds about $10 \%$ at Barrow; thus, the uncertainty in the comparison between $M_{\mathrm{BC}}(\mathrm{COSMOS})\left(\mathrm{PM}_{1}\right)$ and $M_{E C}\left(\mathrm{PM}_{10}\right)$ should be similar at Barrow.

We averaged the $1 \mathrm{~min} M_{\mathrm{BC}}$ (COSMOS) data over the same periods as the individual $M_{\mathrm{EC}}$ observations and compared the $M_{\mathrm{EC}}$ and $M_{\mathrm{BC}}$ (COSMOS) time series (Figure 5). The two measurements agreed very well throughout the year, and the monthly mean of the difference between $M_{\mathrm{BC}}$ (COSMOS) and $M_{\mathrm{EC}}$ did not show any clear seasonal variation (section $A 5$, Figure $A 2$ ). In most months, $M_{\mathrm{BC}}$ (COSMOS) $-M_{\mathrm{EC}}$ was less than $5 \mathrm{ng} \mathrm{m}^{-3}$; this result is consistent with $\triangle M_{\mathrm{BC}}$ estimated in section 4.2. Overall, this comparison indicates that the effect of sea-salt or mineral dust particles on $M_{\mathrm{BC}}$ (COSMOS) was less than $5 \mathrm{ng} \mathrm{m}^{-3}$.

Moreover, $M_{\mathrm{EC}}$ and $M_{\mathrm{BC}}(\mathrm{COSMOS})$ were highly correlated $\left(r^{2}=0.92\right)$ and the slope of the $M_{\mathrm{EC}}-M_{\mathrm{BC}}(\mathrm{COSMOS})$ correlation was 0.99 (Figure 6). Because the COSMOS measurement is based on light absorption, the good

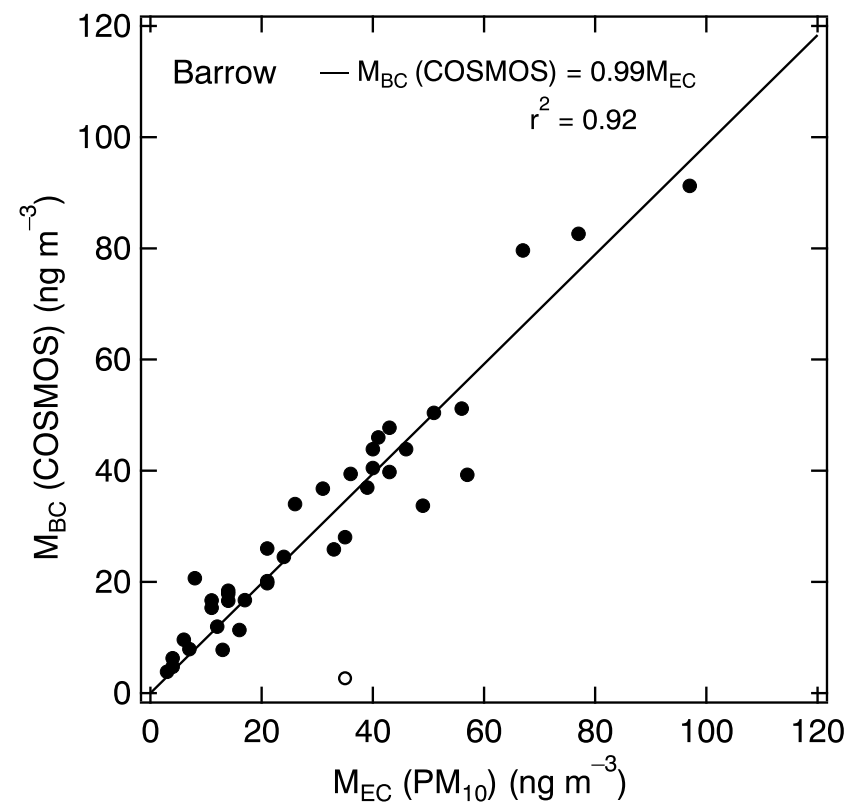

Figure 6. Correlation between $M_{\mathrm{EC}}$ and $M_{\mathrm{BC}}$ (COSMOS) at Barrow during August 2012 and June 2013. One outlier, shown as an open circle, was excluded from the least squares fitting. 


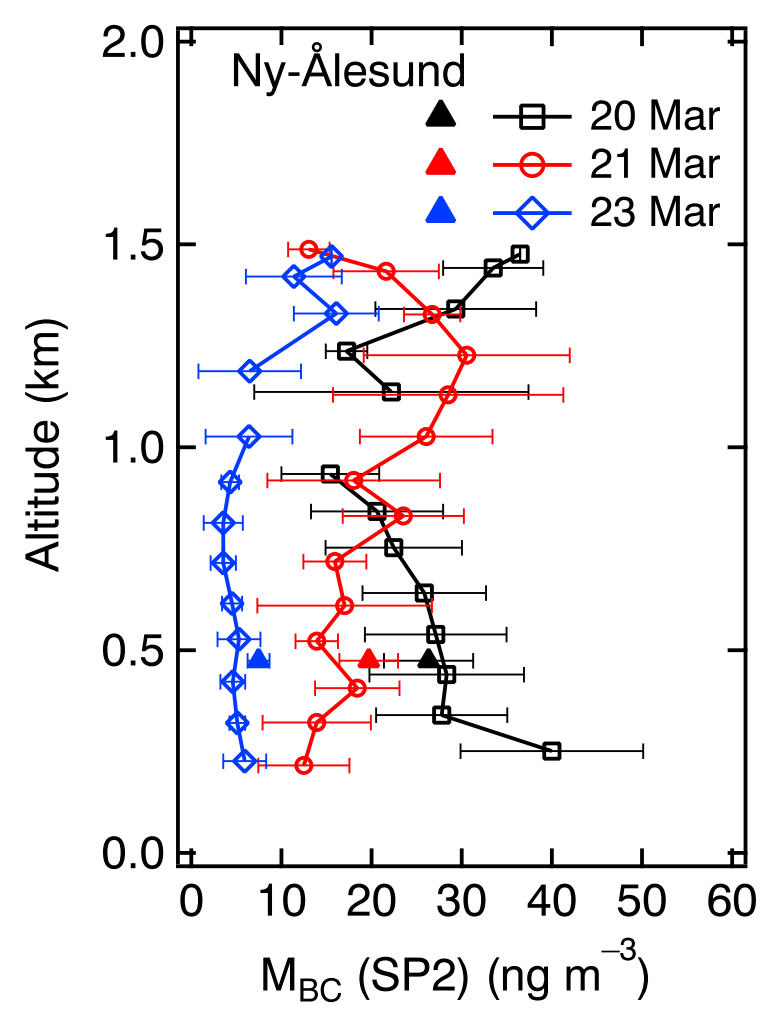

Figure 7. Vertical profiles of $M_{\mathrm{BC}}$ (SP2) measured on 20, 21, and 23 March 2013 during the ACCACIA campaign of aircraft observations. The vertical $M_{\mathrm{BC}}$ (SP2) profiles were obtained at locations within $\pm 0.5^{\circ}$ latitude and $\pm 3^{\circ}$ longitude from the Zeppelin station at Ny-Ålesund. $M_{\mathrm{BC}}$ (SP2) values from every $100 \mathrm{~m}$ altitude interval were binned, and the horizontal bars show the spatial variation $( \pm 1 \sigma)$ in each bin. Daily mean $M_{\mathrm{BC}}$ (COSMOS) values at $\mathrm{Ny}$-Ålesund on the days corresponding to the aircraft observations are shown by triangles.

agreement between $M_{\mathrm{BC}}$ (COSMOS) and $M_{\mathrm{EC}}$ indicates that $\mathrm{BC}$ is the dominant light-absorbing component of aerosols with diameters smaller than $1 \mu \mathrm{m}$ at Barrow. It should be noted here that in Asia, MAC (COSMOS) was determined to be $8.73 \mathrm{~m}^{2} \mathrm{~g}^{-1}$ (or $10.0 \mathrm{~m}^{2} \mathrm{~g}^{-1}$ for $B=1.22$ ) by comparing $M_{\mathrm{BC}}$ (COSMOS) with $M_{\mathrm{BC}}$ (SP2) and $M_{\mathrm{EC}}$ [Kondo et al., 2011b]. The present results indicate that the same MAC (COSMOS) value can be applied to the $\mathrm{BC}$ measurements in the Arctic and they demonstrate the consistency and lack of regional dependence of MAC (COSMOS).

\subsection{Ny-Ålesund}

We compared $M_{\mathrm{BC}}$ (COSMOS) at Ny-Ålesund with aircraft $M_{\mathrm{BC}}$ (SP2) measurements conducted near Zeppelin station, Ny-Ålesund, for 3 days in March 2013, during the Aerosol-Cloud Coupling and Climate Interactions in the Arctic (ACCACIA) campaign [Liu et al., 2015]. Detailed descriptions of the aircraft $M_{B C}$ (SP2) measurements and calibration procedures are provided elsewhere [Liu et al., 2015; McMeeking et al., 2010]. In brief, BC size distributions were measured in the diameter range $D_{\mathrm{BC}}=69-478 \mathrm{~nm}$ and $M_{\mathrm{BC}}(\mathrm{SP} 2)$ was obtained by integrating the $B C$ mass size distributions with an accuracy of about 10\% [Liu et al., 2010].

We estimated $B C$ mass concentrations between $478 \mathrm{~nm}$ and $1000 \mathrm{~nm}$ by fitting a lognormal function to the SP2 data (section A4, Figure A1b) and found that the mean contribution of BC mass concentrations between $478 \mathrm{~nm}$ and $1000 \mathrm{~nm}$ to $M_{\mathrm{BC}}(\mathrm{SP} 2)$ for $\mathrm{PM}_{1}$ was about $15 \%$. In the comparison with $M_{\mathrm{BC}}$ (COSMOS), we corrected the $M_{\mathrm{BC}}(\mathrm{SP} 2)$ data for this additional contribution.

Daily mean $M_{\mathrm{BC}}(C O S M O S)$ at Ny-Ålesund agreed well to within about $3 \%\left(r^{2}=0.96\right)$ with the vertical profiles of $M_{\mathrm{BC}}$ (SP2), in units of $\mathrm{ng} \mathrm{m}^{-3}$ STP, obtained on 20, 21, and 23 March 2013 with an uncertainty of 15\% (Figure 7 and section A6). The absolute difference between $M_{\mathrm{BC}}$ (COSMOS) and $M_{\mathrm{BC}}$ (SP2) was less than $4 \mathrm{ng} \mathrm{m}^{-3}$, despite the temporal and spatial differences of these data (Figure A3). 


\section{COSMOS and PSAP Intercomparison at Barrow and Ny-Ålesund}

Although in this paper we do not present a detailed interpretation of the variability in $b_{\text {scar }}$ it is useful to examine temporal variations of $b_{\text {scar }}$ which is used in equation (2) to derive $b_{\text {abs }}$ (PSAP) at Barrow and Ny-Ålesund. At Barrow, daily $b_{\text {sca }}$ values varied between about 1 and $20 \mathrm{Mm}^{-1}$, with an annual mean of $4.1 \pm 3.5 \mathrm{Mm}^{-1}$ (Figure $8 \mathrm{a}$ ); wintertime $b_{\mathrm{abs}} / \mathrm{b}_{\mathrm{sca}}$ ratios were higher by a factor of about 1.5 than the summertime ratios, and, as a result, the wintertime single scattering albedo, defined as SSA $=b_{\text {sca }} /\left(b_{\text {abs }}(\mathrm{PSAP})+b_{\text {sca }}\right)$, of $0.94 \pm 0.03$, was lower than the summertime value $(0.96 \pm 0.04)$ (section A7). At Ny-Ålesund, daily $b_{\text {sca }}$ values ranged between about 0.1 and $18 \mathrm{Mm}^{-1}$, with an annual mean of $4.0 \pm 3.5 \mathrm{Mm}^{-1}$ (Figure $8 \mathrm{~b}$ ), and wintertime $b_{\mathrm{abs}} / b_{\mathrm{sca}}$ ratios were higher by a factor of about 1.3 than the summertime ratios. The corresponding SSA values were $0.95 \pm 0.05$ and $0.96 \pm 0.04$ in winter and summer, respectively (section A7). These results suggest that the contribution of absorbing particles to the total aerosol extinction coefficient was larger during winter at both sites.

We also compared $b_{\mathrm{abs}}$ (COSMOS) and $b_{\mathrm{abs}}$ (PSAP) at Barrow and Ny-Ålesund. At Barrow, about $36 \%$ of the daily $b_{\text {abs }}$ (PSAP) values were less than $0.1 \mathrm{Mm}^{-1}$ and $b_{\text {abs }}$ (PSAP) rarely exceeded $1 \mathrm{Mm}^{-1}$ (Figure 8a), whereas at Ny-Ålesund, about $60 \%$ of $b_{\text {abs }}$ values were less than $0.1 \mathrm{Mm}^{-1}$ and higher values $\left(b_{\mathrm{abs}}>1 \mathrm{Mm}^{-1}\right)$ were seldom observed (Figure $8 \mathrm{~b}$ ).

$b_{\text {abs }}(\mathrm{PSAP})\left(\mathrm{PM}_{1}\right)$ was highly correlated with $b_{\text {abs }}(\mathrm{PSAP})\left(\mathrm{PM}_{10}\right)\left(r^{2}=0.97\right)$ at Barrow (Figure 9a). The slope of the correlation, denoted as $\beta$, was 0.85 . Even when the symmetrical least squares fit was computed, $\beta$ was little changed owing to the relatively high correlation between the parameters $\left(r^{2}>0.82\right)$.

Light-absorbing particles with diameters larger than $1 \mu \mathrm{m}$, including mineral dust particles and $\mathrm{BC}$, likely contribute to $b_{\text {abs }}$ (PSAP) for $\mathrm{PM}_{10}$. In addition, correction of the scattering effects may be size-dependent, which is not fully taken into account by the correction made with equation (2). As discussed in section 5.1, it is unlikely that the $\mathrm{BC}$ mass concentration fraction with particle diameters larger than $1 \mu \mathrm{m}$ exceeds $10 \%$. Moreover, the MAC for BC particles larger than $1 \mu \mathrm{m}$ is considerably smaller than that for $B C$ particles smaller than $1 \mu \mathrm{m}$ [Schwarz et al., 2013]. Therefore, it is likely that the contribution of BC particles larger than $1 \mu \mathrm{m}$ is limited. It is difficult to identify the reason for the slope being less than 1 , owing to the lack of sufficient data necessary to quantify these effects.

$b_{\text {abs }}$ (COSMOS) was highly correlated with both $b_{\text {abs }}$ (PSAP) for $\mathrm{PM}_{1}\left(r^{2}=0.87 ; \beta=0.82\right)$ and $\mathrm{PM}_{10}\left(r^{2}=0.88\right.$; $\beta=0.72$ ) at Barrow, although some data points deviated significantly from the least squares fitted line (Figures $9 \mathrm{~b}$ and $9 \mathrm{c}$ ). The $\beta$ value of 0.72 is largely explained by the product of the slopes $=0.85$ (PSAP $\left.\left(\mathrm{PM}_{10}\right)-\operatorname{PSAP}\left(\mathrm{PM}_{1}\right)\right) \times 0.82\left(\mathrm{COSMOS}-\operatorname{PSAP}\left(\mathrm{PM}_{1}\right)\right)=0.70$.

It is possible that the $b_{\mathrm{abs}}$ (PSAP)- $b_{\mathrm{abs}}$ (COSMOS) correlation with $\beta$ less than 1 and the occasional large scatter between $b_{\text {abs }}$ (PSAP) and $b_{\text {abs }}$ (COSMOS) for $\mathrm{PM}_{1}$ at Barrow are partly due to differences in the methodology used to derive $b_{\text {abs }}$ : equation (2) for PSAP data, whereas equation (4) for COSMOS data. The subtraction of the effect of scattering by non-BC aerosols in equation (2) may add uncertainty to the absolute accuracy and precision of $b_{\text {abs }}$ (PSAP). In addition, light absorption of internally mixed BC particles collected on filters is enhanced by the lens effect in a PSAP, whereas this effect is negligibly small for COSMOS, as discussed in section 2. Further, there may exist volatile light-absorbing aerosol species that affect $b_{\mathrm{abs}}$ (PSAP) but not $b_{\mathrm{abs}}$ (COSMOS). The combined effect of these factors is that nonabsorbing coatings or non-BC absorbers may contribute to an enhancement of up to $22 \%(1 / 0.82)$ of the absorption of uncoated BC particles. It should be noted that differences in the absolute value of $b_{\mathrm{abs}}$ do not influence the $M_{\mathrm{BC}}$ values derived from PSAP data, as discussed below.

At Ny-Ålesund, $b_{\mathrm{abs}}$ (COSMOS) and $b_{\mathrm{abs}}$ (PSAP) for $\mathrm{PM}_{10}$ were also correlated $\left(r^{2}=0.82 ; \beta=0.70\right)$ (Figure 9d). $b_{\mathrm{abs}}$ (PSAP) was higher than $b_{\mathrm{abs}}$ (COSMOS) by $43 \%(1 / 0.70)$ at Ny-Ålesund $\left(\mathrm{PM}_{10}\right)$. The slope $(0.70)$ agrees with that obtained at Barrow to within $3 \%$. Because $\beta$ for $\mathrm{PM}_{10}$ was similar between the two sites, we used $b_{\text {abs }}$ (PSAP) for $\mathrm{PM}_{10}$ to derive $M_{\mathrm{BC}}$ at Ny-Ålesund.

Finally, it is possible to derive the mass concentration of $\mathrm{BC}$ by using the $b_{\mathrm{abs}}$ (PSAP) data and applying these empirically determined relationships. Equation (10) is the condition of scaling of $M_{\mathrm{BC}}$ (PSAP) by $M_{\mathrm{BC}}$ (COSMOS):

$$
M_{\mathrm{BC}}(\mathrm{PSAP})=M_{\mathrm{BC}}(\mathrm{COSMOS})
$$



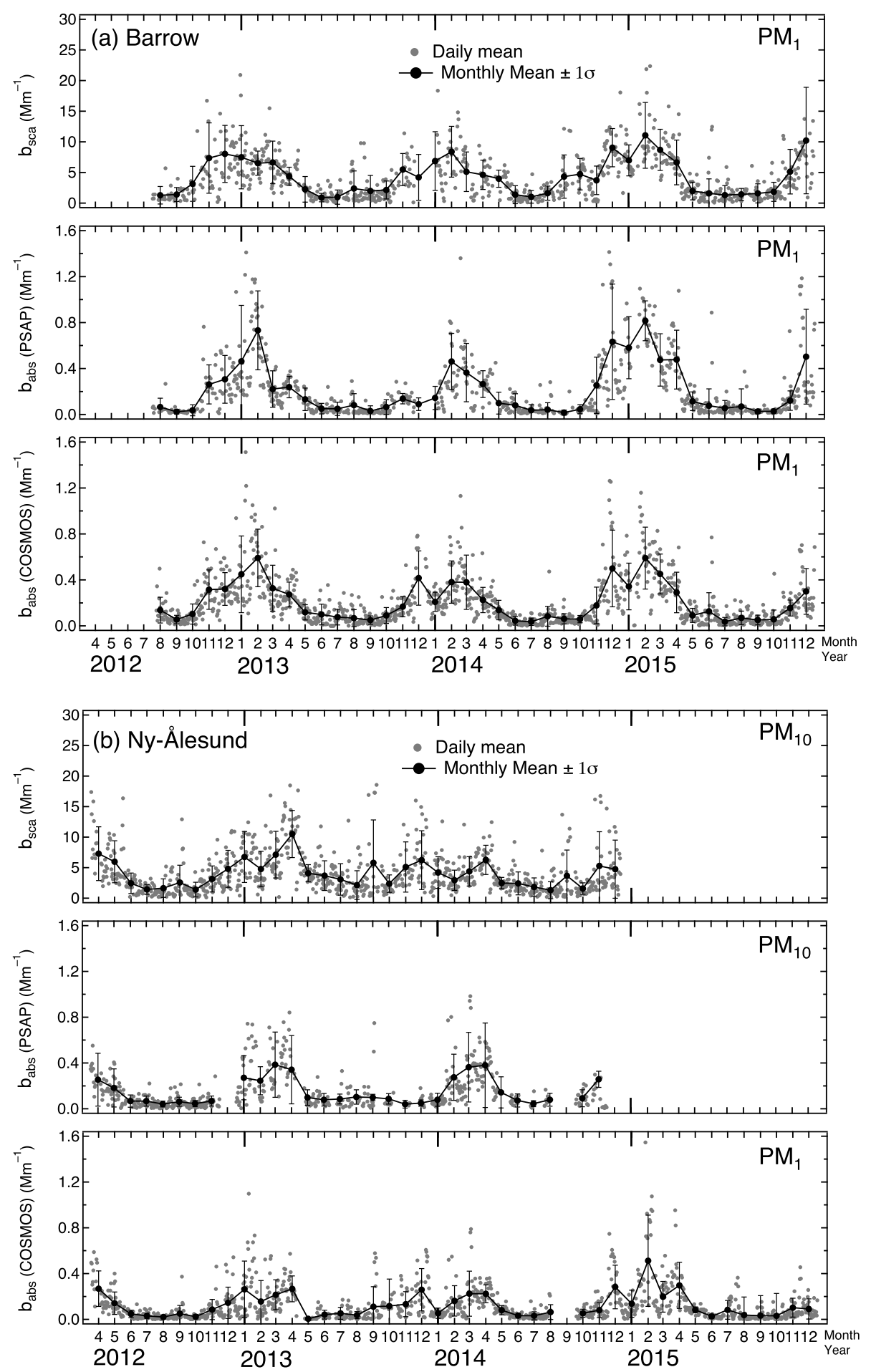

Figure 8. (a) Daily and monthly mean values of $b_{\text {sca }}$ (measured by nephelometer), $b_{\mathrm{abs}}$ (PSAP), and $b_{\mathrm{abs}}$ (COSMOS) for PM at Barrow from 2012 to 2015. (b) Same as Figure 8a but at Ny-Ålesund for $\mathrm{PM}_{10}$ during 2012-2014. The gaps in the PSAP and COSMOS data at Ny-Ålesund are due to the data quality assurance procedure.

At Barrow,

$$
M_{\mathrm{BC}}(\mathrm{PSAP})=\beta \times b_{\mathrm{abs}}(\mathrm{PSAP}) / \mathrm{MAC}(\mathrm{COSMOS}),
$$

where $\beta=0.82 \pm 0.01( \pm 1 \sigma)$, and MAC $(\operatorname{COSMOS})=8.73 \mathrm{~m}^{2} \mathrm{~g}^{-1}$. 

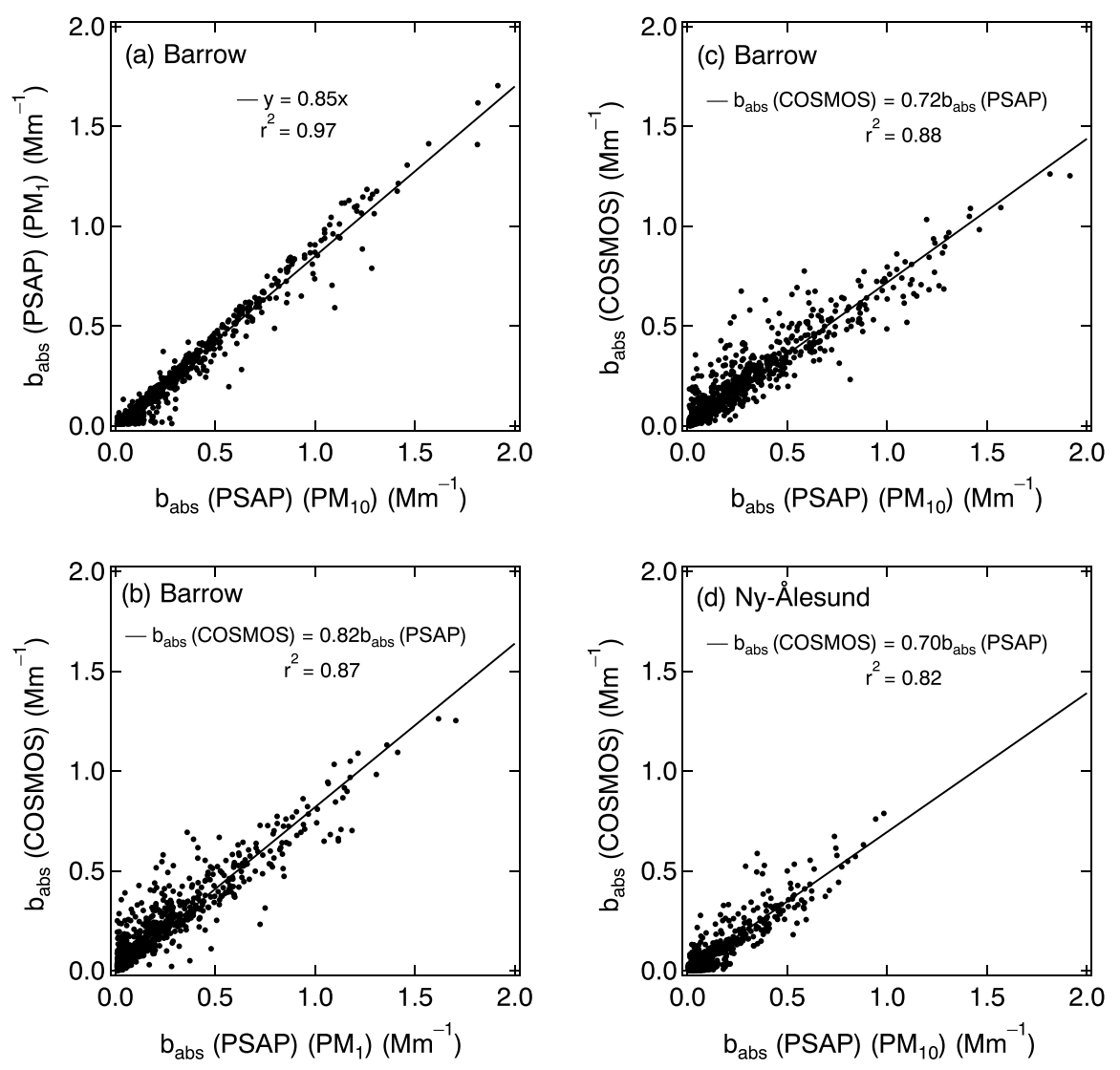

Figure 9. Scatterplots between daily mean (a) $b_{\mathrm{abs}}$ (PSAP) for $\mathrm{PM}_{1}$ and $b_{\mathrm{abs}}$ (PSAP) for $\mathrm{PM}_{10}$ and between daily mean $b_{\text {abs }}$ (COSMOS) and $b_{\mathrm{abs}}$ (PSAP) for (b) $\mathrm{PM}_{1}$ and (c) $\mathrm{PM}_{10}$ at Barrow during 2012-2015. (d) Scatterplot between daily mean $b_{\mathrm{abs}}$ (COSMOS) and $b_{\mathrm{abs}}$ (PSAP) for $\mathrm{PM}_{10}$ at Ny-Ålesund during 2012-2014.

MAC (PSAP) is expressed as follows:

$$
\text { MAC }(\mathrm{PSAP})=\mathrm{MAC}(\mathrm{COSMOS}) / \beta,
$$

where MAC (PSAP) $=10.6 \pm 0.2 \mathrm{~m}^{2} \mathrm{~g}^{-1}$ for $\mathrm{PM}_{1}$. At Ny-Ålesund, $\beta=0.70 \pm 0.01$ and MAC (PSAP) $=12.5 \pm 0.2 \mathrm{~m}^{2} \mathrm{~g}^{-1}$ for $\mathrm{PM}_{10}$.

MAC (PSAP) values were also derived for each year by using the corresponding comparison between COSMOS and PSAP measurements at Barrow and Ny-Ålesund. The derived MAC (PSAP) values varied between 8.5 and $11.8 \mathrm{~m}^{2} \mathrm{~g}^{-1}\left(\mathrm{PM}_{1}\right)$ during 2012-2015 at Barrow and between 9.5 and $13.4 \mathrm{~m}^{2} \mathrm{~g}^{-1}\left(\mathrm{PM}_{10}\right)$

Table 2. Slopes and Correlation Coefficients of the Relationship Between $b_{\mathrm{abs}}$ (COSMOS) and $b_{\mathrm{abs}}$ (PSAP) at Barrow (August 2012 to December 2015) and Ny-Ålesund (April 2012 to December 2014) in Individual Years and the Corresponding MAC (PSAP) Values ${ }^{\mathrm{a}}$

\begin{tabular}{lccccccc} 
& \multicolumn{4}{c}{ Barrow } & & \multicolumn{3}{c}{ Ny-Ålesund } \\
\cline { 2 - 3 } \cline { 7 - 8 } ear & Slope $\pm 1 \sigma$ & $r^{2}$ & MAC (PSAP) $\left(\mathrm{m}^{2} \mathrm{~g}^{-1}\right)$ & & Slope $\pm 1 \sigma$ & $r^{2}$ & MAC (PSAP) $\left(\mathrm{m}^{2} \mathrm{~g}^{-1}\right)$ \\
\hline 2012 & $1.07 \pm 0.049$ & 0.76 & 8.5 & & $0.92 \pm 0.031$ & 0.72 & 9.5 \\
2013 & $0.92 \pm 0.016$ & 0.89 & 9.5 & & $0.65 \pm 0.016$ & 0.82 & 13.4 \\
2014 & $0.82 \pm 0.014$ & 0.91 & 10.7 & & $0.65 \pm 0.010$ & 0.92 & 13.4 \\
2015 & $0.74 \pm 0.010$ & 0.92 & 11.8 & & & \\
Average 1 & & & $10.1 \pm 1.4$ & & & $12.1 \pm 2.3$ \\
Average 2 & $0.82 \pm 0.01$ & 0.87 & $10.6 \pm 0.2$ & & $0.72 \pm 0.01$ & 0.82 & $12.5 \pm 0.2$ \\
\hline
\end{tabular}

\footnotetext{
${ }^{a}$ Average 1 was calculated by averaging the MAC (PSAP) values of the individual years. Average 2 are the regression
} results and the MAC (PSAP) value derived from the correlation of all $b_{\text {abs }}$ (PSAP) and $b_{\text {abs }}$ (COSMOS) values. 

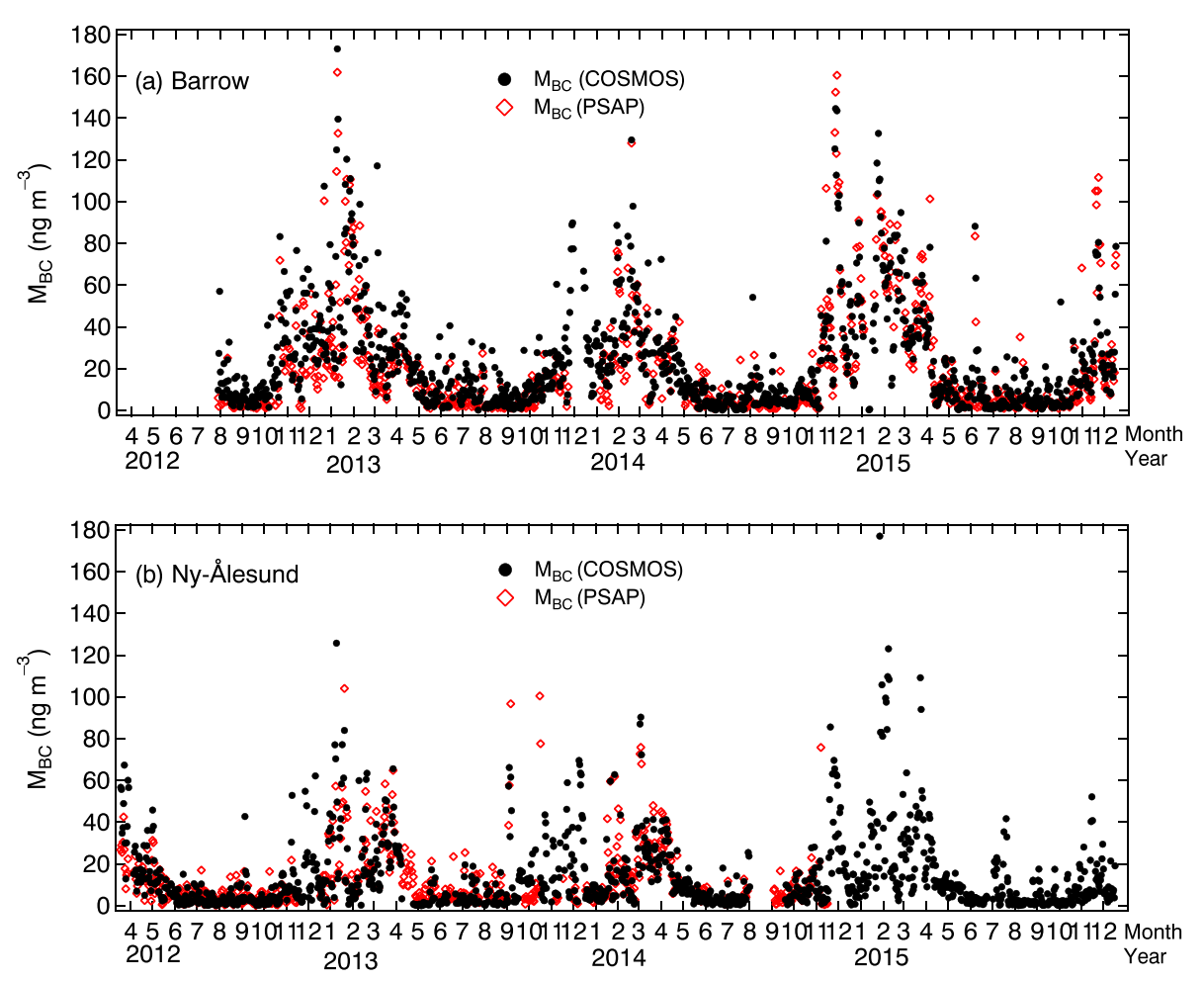

Figure 10. Time series of daily mean $M_{\mathrm{BC}}$ (COSMOS) and $M_{\mathrm{BC}}$ (PSAP) at (a) Barrow (2012-2015) and (b) Ny-Ålesund (2012-2015).

during 2012-2014 at Ny-Ålesund (Table 2). At Barrow, we estimated the MAC (PSAP) accuracy to be about $18 \%$, taking into account the slope determination accuracy of about $2 \%$, the $M_{\mathrm{BC}}$ (COSMOS) accuracy of

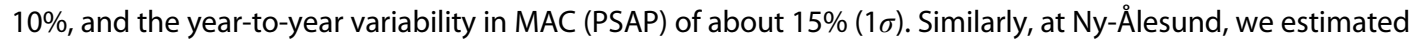
the accuracy of MAC (PSAP) to be about $20 \%$, taking into account the year-to-year variability in MAC (PSAP) of about $18 \%(1 \sigma)$.

We examined time series of daily mean $M_{\mathrm{BC}}$ (COSMOS) and $M_{\mathrm{BC}}$ (PSAP) for the entire period (2012-2015) of COSMOS measurements at both sites to evaluate the consistency of these two instruments (Figure 10). The temporal variations of $M_{\mathrm{BC}}$ (COSMOS) and those of $M_{\mathrm{BC}}$ (PSAP) were generally well correlated over wide ranges of values, as expected from the high correlation between $b_{\text {abs }}$ (PSAP) and $b_{\text {abs }}$ (COSMOS) (Figure 9) and the scaling of $b_{\text {abs }}$ (PSAP) in equation (10). The time series qualitatively show the degree of the differences between individual daily mean values of $M_{B C}$ (COSMOS) and $M_{B C}$ (PSAP). The difference between monthly mean $M_{\mathrm{BC}}$ (COSMOS) and $M_{\mathrm{BC}}$ (PSAP) values was generally less than $10 \mathrm{ng} \mathrm{m}^{-3}$ (section A8.1, Figure A5) and agreed to within $5 \%\left(r^{2}=0.96\right)$ and $2 \%\left(r^{2}=0.95\right)$ at Barrow and Ny-Ålesund, respectively (section A8.2, Figure A6). It is not known whether the relationship between the PSAP and COSMOS measurements observed in the Arctic holds at other latitudes.

\section{Temporal Variations of $M_{\mathrm{BC}}$}

\subsection{Year-to-Year Variability}

$M_{\mathrm{BC}}$ (COSMOS) did not show well-defined diurnal variations (monthly mean diurnal variation $<10 \%$ of the daily mean) at these sites during any part of the year (section A9), suggesting that localized BC emissions from anthropogenic activities had little influence on the measured $M_{\mathrm{BC}}$.

It is important to investigate year-to-year variations of $M_{\mathrm{BC}}$ in the Arctic with reliable data sets because yearto-year variations in $\mathrm{BC}$ emissions and transport pathways can be reflected in $M_{\mathrm{BC}}$ changes. As we showed in section 6, it is possible to use $M_{\mathrm{BC}}$ (PSAP) for this purpose. We examined time series of monthly mean $M_{\mathrm{BC}}$ (PSAP) from January 1998 to July 2012 at Barrow and from April 2006 to March 2012 at Ny-Ålesund. 


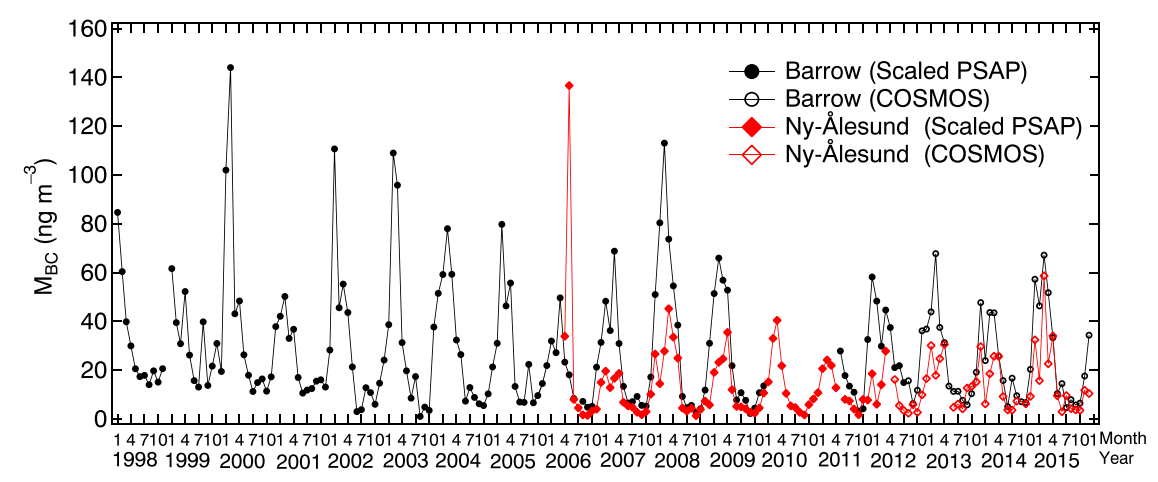

Figure 11. Time series of monthly mean $M_{B C}$ (PSAP) values at Barrow (January 1998 to July 2012) (closed circles) and NyÅlesund (April 2006 to March 2012) (closed diamonds). The series are extended to December 2015 with $M_{\mathrm{BC}}$ (COSMOS) values at Barrow (open circles) and Ny-Ålesund (open diamonds). The gap in the PSAP data at Barrow from January 2010 to April 2011 was caused by an instrument malfunction.

Monthly mean $M_{\mathrm{BC}}$ (COSMOS) values at these sites also partly overlap these time series and extend them up to December 2015 (Figure 11). PSAP data are missing at Barrow from January 2010 to April 2011 because of an instrument malfunction.

In winter, $M_{\mathrm{BC}}$ showed year-to-year variations of up to a factor of two with a relative variability of about $22 \%$ $(1 \sigma)$. In summer, $M_{\mathrm{BC}}$ was much lower than it was in winter and year-to-year variability in $M_{\mathrm{BC}}$ was correspondingly lower; the relative variability in $M_{\mathrm{BC}}$ was about $36 \%(1 \sigma)$ in summer. Year-to-year variability can be caused by variations in $\mathrm{BC}$ emissions, especially those due to biomass burning, as well as by differences in the transport pathway and the degree of the wet deposition of $\mathrm{BC}$ during transport.

Relatively high $M_{\mathrm{BC}}$ values were observed in winter 2008 at Barrow (Figure 11). During winter 2008, the BC profiles observed by the Aerosol, Radiation, and Cloud Processes affecting Arctic Climate aircraft observations indicated downward transport of BC from the free troposphere to the planetary boundary layer over the Alaskan Arctic [Spackman et al., 2010; Brock et al., 2011]; these findings suggest that biomass burning events in Siberia (Russia) and Kazakhstan influenced the surface-measured $M_{\mathrm{BC}}$ at Barrow in winter 2008. More detailed studies of the effects of the temporal variations of the emission and transport of $B C$ on the surface $M_{\mathrm{BC}}$ in the Arctic require simulations with sophisticated numerical models, which are beyond the scope of this study.

\subsection{Long-Term Trends}

At Barrow, Quinn et al. [2007] showed that there was a significant decreasing trend in $b_{\text {abs }}$ (PSAP) (PM 10 ) at $550 \mathrm{~nm}$ in the months of March and April between 1998 and 2006. Here we extended the period of the measurements to 1998-2015 and investigated the long-term changes of $M_{B C}$ (PSAP) in winter and summer.

We applied the least squares (LS) method to time series of $M_{\mathrm{BC}}$ (PSAP) averaged over winter and summer seasons from 1998 to 2015 to obtain regression lines (Figure 12). The slopes derived by the LS method were $-0.56 \pm 0.45 \mathrm{ng} \mathrm{m}^{-3} \mathrm{yr}^{-1}\left(-1.3 \% \mathrm{yr}^{-1}\right)$ with $r^{2}=0.10$ for winter and $-0.53 \pm 0.17 \mathrm{ng} \mathrm{m}^{-3} \mathrm{yr}^{-1}\left(-4.7 \% \mathrm{yr}^{-1}\right)$ with $r^{2}=0.50$ for summer (Table 3 ).

It is noteworthy that after 2001, the changes in $M_{B C}$ (PSAP) were small in summer (Figure 12). We therefore excluded the data for the initial 3 years and recalculated the slopes, obtaining values of $-0.43 \pm 0.56 \mathrm{ng} \mathrm{m}^{-3} \mathrm{yr}^{-1}\left(-1.3 \% \mathrm{yr}^{-1}\right)$ with $r^{2}=0.05$ for winter and $-0.23 \pm 0.13 \mathrm{ng} \mathrm{m}^{-3} \mathrm{yr}^{-1}\left(-1.7 \% \mathrm{yr}^{-1}\right)$ with $r^{2}=0.20$ for summer (Table 3). We also derived the $M_{\mathrm{BC}}$ (PSAP) trends for 3 month periods between 1998 and 2015, but $r^{2}$ values were not substantially improved (section A10).

We also estimated the trends by a regression analysis of $M_{\mathrm{BC}}$ (PSAP) at Barrow against time based on the Bayesian statistical method [e.g., Hoff, 2009] (section A10). The expected value of the slope and its uncertainty were evaluated as the mean and standard deviation, respectively, of $\sim 2 \times 10^{5}$ sampling points over the slopeintercept space obtained by the Markov chain Monte Carlo (MCMC) method. The trends derived by the 


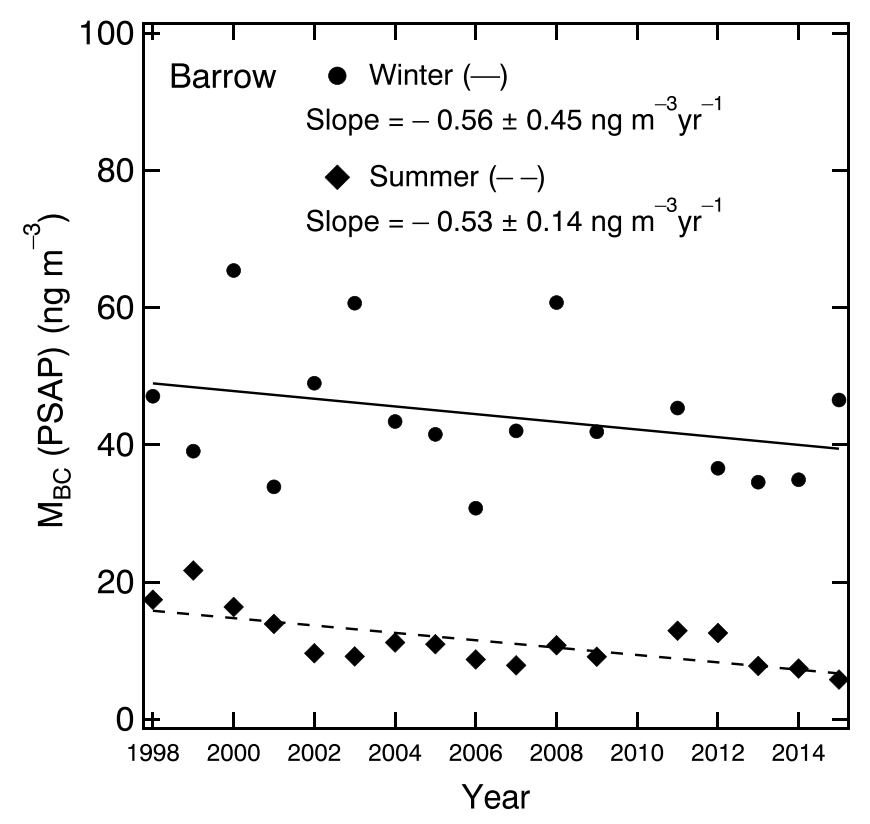

Figure 12. Time series of monthly mean $M_{\mathrm{BC}}$ (PSAP) in winter (November-April) and summer (May-October) during 1998-2015 at Barrow. The circles (winter) and diamonds (summer) represent seasonally averaged $M_{\mathrm{BC}}$ (PSAP) values. The regression lines were obtained by applying the least squares method to the $M_{\mathrm{BC}}$ (PSAP) time series.

MCMC method were statistically insignificant (not shown), although slopes were obtained for 3 month periods between 1998 and 2015 (Table A1). Both the LS and MCMC results indicate that it is difficult to derive the slopes of long-term $M_{\mathrm{BC}}$ (PSAP) changes accurately for the period 1998-2015. The lack of statistical reliability is due to the large year-to-year variability in $M_{B C}$ (PSAP), which potentially includes the year-to-year variability of MAC (PSAP) (maximum about 20\%; section A8.1).

Collaud Coen et al. [2013] derived $b_{\text {abs }}$ (PSAP) $\left(\mathrm{PM}_{10}\right)$ trends at Barrow for the periods 1998-2010 and 20012010 by a different method and obtained slopes of $-1.3 \% \mathrm{yr}^{-1}$ (1998-2010) and $-6.5 \% \mathrm{yr}^{-1}$ (2001-2010). The much smaller slope for 1998-2009 than for 2001-2010 is qualitatively consistent with our analysis. However, they used different parameters. First, they used $\mathrm{PM}_{10}$ data, whereas we used $\mathrm{PM}_{1}$ data, and second, they did not exclude the 2010 data, whereas we excluded anomalously low $2010 \mathrm{PM}_{1}$ values caused by a malfunction of the PSAP (section 7.1, Figure 11).

We could not perform a similar trend analysis of the Ny-Ålesund data owing to the lack of $M_{\mathrm{BC}}$ (PSAP) data with sufficient reliability prior to 2006.

\subsection{Seasonal Variations}

At Barrow, the monthly mean $M_{\mathrm{BC}}$ (COSMOS) averaged over the 3 year period from 2012 to 2015 agreed with the $M_{\mathrm{BC}}$ (PSAP) values averaged over the 10 year period from January 2005 to December 2015 to within 10\% (Figure 13a), as expected from the trend analysis discussed in section 7.2. At Ny-Ålesund, monthly mean $M_{\mathrm{BC}}$

Table 3. Trends of Seasonally Averaged $M_{\mathrm{BC}}$ (PSAP) Between 1998 and 2015 at Barrow ${ }^{\mathrm{a}}$

\begin{tabular}{lcc} 
Season & Slope $\left(\mathrm{ng} \mathrm{m}^{-3} \mathrm{yr}^{-1}\right) \pm 1 \sigma$ & $r^{2}$ \\
\hline Winter (November-April) & $-0.56 \pm 0.45$ & 0.10 \\
Summer (May-October) & $-0.53 \pm 0.14$ & 0.50 \\
Winter 2001-2015 & $-0.43 \pm 0.56$ & 0.05 \\
Summer 2001-2015 & $-0.23 \pm 0.13$ & 0.20 \\
\hline
\end{tabular}

\footnotetext{
${ }^{a}$ Linear trends estimated by least squares fitting are shown together with their $\pm 1 \sigma$ and $r^{2}$ values. The trends derived
} for $M_{\mathrm{BC}}$ (PSAP) in winter (2001-2015) and summer (2001-2015) are also shown for comparison. 

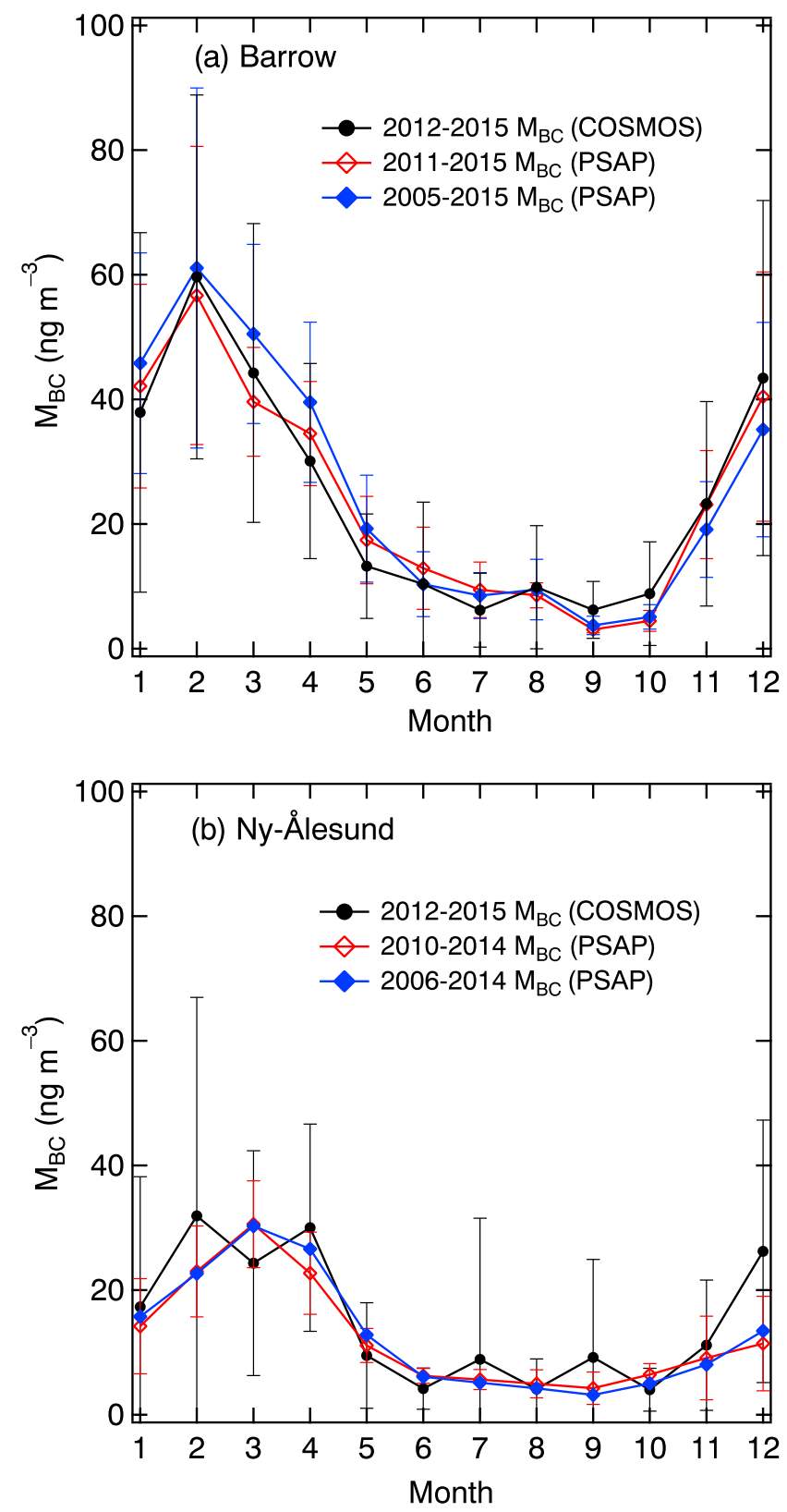

Figure 13. (a) Monthly mean $M_{\mathrm{BC}}$ (PSAP) at Barrow averaged over 5 years (2011-2015) and 10 years (2005-2015). (b) Monthly mean $M_{\mathrm{BC}}$ (PSAP) at Ny-Ålesund averaged over 5 years (2010-2014) and 8 years (2006-2015). Monthly mean $M_{\mathrm{BC}}$ (COSMOS) averaged over 2012-2015 is also shown in each panel. The vertical bars represent the standard deviations $( \pm 1 \sigma)$ of the monthly mean values.

instruments have been widely used for continuous measurements of $M_{\mathrm{BC}}$ in the Arctic. Hirdman et al. [2010a, 2010b] reported $M_{\mathrm{BC}}$ values at Barrow and Ny-Ålesund based on measurements made by PSAP instruments, but they used different methods to derive $M_{\mathrm{BC}}$. Because of the methodological differences, we denote $M_{\mathrm{BC}}$ values derived by these previous studies as $M_{\mathrm{BC}}{ }^{*}\left(\mathrm{PSAP}-\mathrm{PM}_{1}\right)$ for Barrow and $M_{\mathrm{BC}}{ }^{*}$ (PSAP-PM 10 ) for NyÅlesund in comparisons with our $M_{\mathrm{BC}}$ (PSAP) values, which were scaled by $M_{\mathrm{BC}}$ (COSMOS). The values of $M_{\mathrm{BC}}{ }^{*}\left(\mathrm{PSAP}-\mathrm{PM}_{1}\right)$ and $M_{\mathrm{BC}}{ }^{*}\left(\mathrm{PSAP}-\mathrm{PM}_{10}\right)$ were obtained from Hirdman et al. [2010a, Figure 2].

We compared monthly mean $M_{\mathrm{BC}}{ }^{*}\left(\mathrm{PSAP}-\mathrm{PM}_{1}\right), M_{\mathrm{BC}}{ }^{*}$ (PSAP-PM $\mathrm{P}_{10}$ ), and $M_{\mathrm{BC}}$ (aethalometer) variations with monthly mean $M_{\mathrm{BC}}$ (COSMOS) and $M_{\mathrm{BC}}$ (PSAP) variations (Figure 14). The values of $M_{\mathrm{BC}}$ (aethalometer) at 

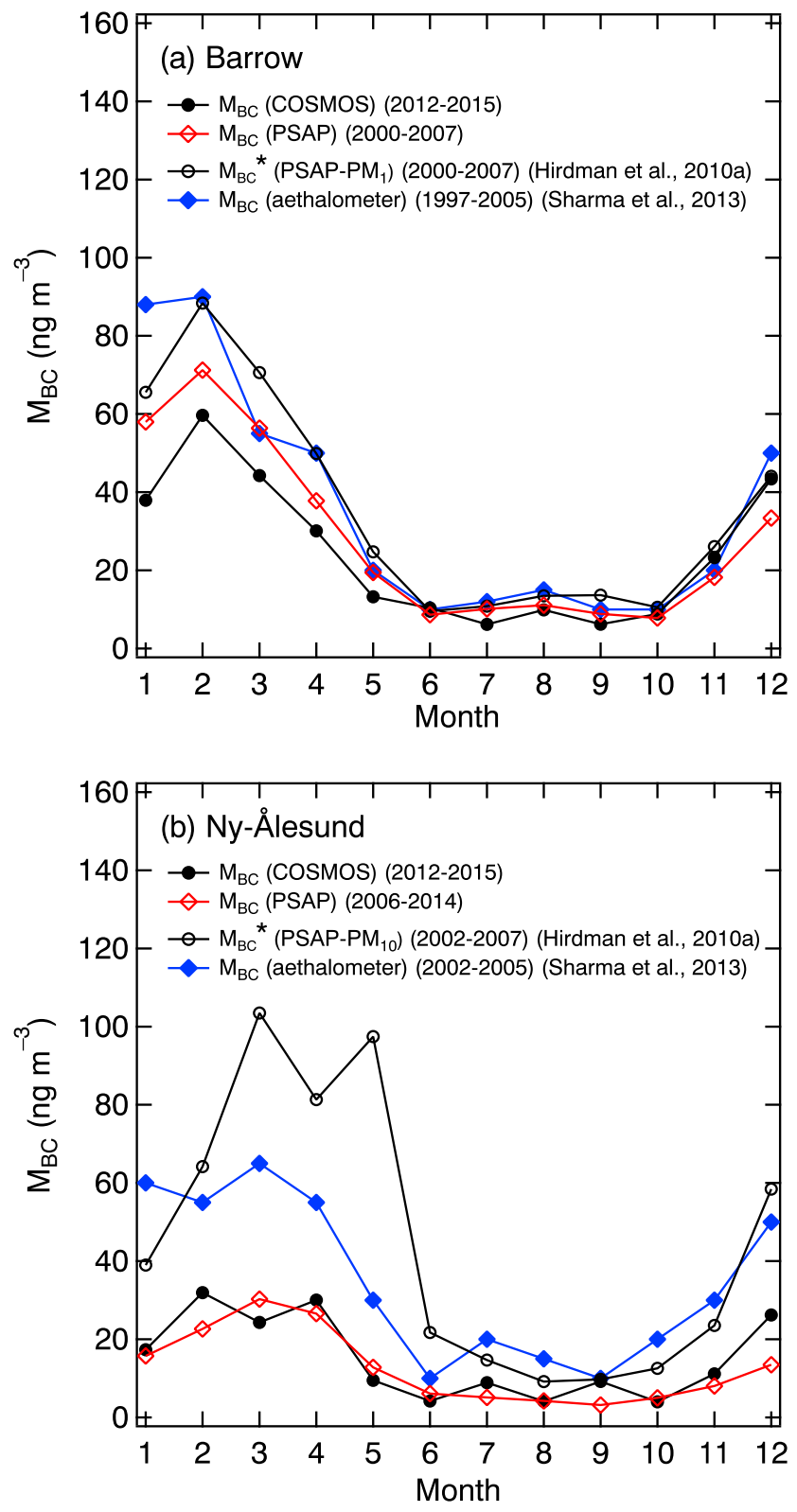

Figure 14. Comparisons of monthly mean $M_{B C}{ }^{*}\left(P S A P-P M_{1}\right), M_{B C}{ }^{*}$ (PSAP$\mathrm{PM}_{10}$ ), and $M_{\mathrm{BC}}$ (aethalometer) with $M_{\mathrm{BC}}$ (COSMOS) and $M_{\mathrm{BC}}$ (PSAP) at (a) Barrow and (b) Ny-Ålesund. The $M_{B C}{ }^{*}\left(P S A P-P M_{1}\right)$ data at Barrow (2000-2007) and $M_{\mathrm{BC}}{ }^{*}$ (PSAP-PM 10 ) data at Ny-Ålesund (2002-2007) are those obtained by Hirdman et al. [2010a], and the $M_{\mathrm{BC}}$ (aethalometer) data at Barrow (1997-2005) and Ny-Ålesund (2002-2005) are those obtained by Sharma et al. [2013]. in the MAC values because they differ by a factor of only about 1.25. Thus, there must be other unidentified problems with the derivation of the $\mathrm{PM}_{10}$ absorption coefficient at Ny-Ålesund prior to 2006.

The $M_{\mathrm{BC}}$ (aethalometer) $/ M_{\mathrm{BC}}$ (PSAP) ratio was about 3.0 in winter and about 3.1 in summer. The values of $M_{\mathrm{BC}}$ (aethalometer) at Ny-Ålesund were taken from Sharma et al. [2013, Figure 6c]. The period of the $M_{\mathrm{BC}}$ (aethalometer) measurements (2002-2005) does not overlap the period of the $M_{\mathrm{BC}}$ (PSAP) measurements (20072014), but it is unlikely that these large ratios can be explained by the long-term trend in $M_{\mathrm{BC}}$ (PSAP), as discussed above.

The ratio of the $M_{\mathrm{BC}}$ (COSMOS) at Barrow to that at Ny-Ålesund in winter was about $1.77 \pm 0.42$. The corresponding $M_{\mathrm{BC}}$ (aethalometer) and $M_{\mathrm{BC}}{ }^{*}\left(\mathrm{PSAP}-\mathrm{PM}_{1}\right)$ ratios were $0.81 \pm 0.13$ and $0.52 \pm 0.23$, respectively. 
Table 4. Ratio of Scaled $M_{\mathrm{BC}}$ (PSAP) and $M_{\mathrm{BC}}$ Measured by Previous Studies by Using a PSAP ( $M_{\mathrm{BC}}{ }^{*}$ (PSAP)) and an Aethalometer ( $M_{\mathrm{BC}}$ (Aethalometer)) at Barrow and Ny-Ålesund in Winter (November-April) and Summer (May-October)

\begin{tabular}{|c|c|c|c|c|}
\hline \multirow[b]{2}{*}{ Season } & \multicolumn{2}{|c|}{ Barrow } & \multicolumn{2}{|c|}{ Ny-Ålesund } \\
\hline & $\begin{array}{c}M_{\mathrm{BC}}{ }^{*}\left(\mathrm{PSAP}-\mathrm{PM} \mathrm{M}_{1}\right) / M_{\mathrm{BC}} \\
(\mathrm{PSAP})\end{array}$ & $\begin{array}{c}M_{\mathrm{BC}} \text { (aethalometer)/M } / M_{\mathrm{BC}} \\
\text { (PSAP) }\end{array}$ & $\begin{array}{c}M_{\mathrm{BC}}{ }^{*}\left(\mathrm{PSAP}-\mathrm{PM} \mathrm{M}_{10}\right) / M_{\mathrm{BC}} \\
(\mathrm{PSAP})\end{array}$ & $\begin{array}{c}M_{\mathrm{BC}} \text { (aethalometer) } / M_{\mathrm{BC}} \\
\text { (PSAP) }\end{array}$ \\
\hline Winter & 1.28 & 1.28 & 3.18 & 2.98 \\
\hline Summer & 1.26 & 1.19 & 3.63 & 3.09 \\
\hline
\end{tabular}

Reliable ratios, such as those obtained by the present study, are important for improving our understanding of the spatial variability in $M_{\mathrm{BC}}$ in the Arctic.

\section{Summary and Conclusion}

Although long-term particle soot absorption photometer (PSAP) measurements of the light absorption coefficient $\left(b_{\mathrm{abs}}\right)$ ( $b_{\mathrm{abs}}$ (PSAP)) have been reported by previous studies at Barrow, Alaska, and Ny-Ålesund, Spitsbergen, in the Arctic, those studies did not critically evaluate the effects on $b_{\text {abs }}$ (PSAP) of aerosols coexisting with $\mathrm{BC}$. Furthermore, they used different mass absorption cross section (MAC) values to convert $b_{\mathrm{abs}}$ to BC mass concentrations. We measured $b_{\mathrm{abs}}$ at these sites for about 3 years by using COSMOS $\left(b_{\mathrm{abs}}\right.$ (COSMOS)), which uses a heated inlet to remove non-BC compounds, and then evaluated the performance of COSMOS for the measurement of $\mathrm{BC}$ mass concentrations $\left(M_{\mathrm{BC}}(\mathrm{COSMOS})\right)$ with particle diameters less than $1 \mu \mathrm{m}\left(\mathrm{PM}_{1}\right)$ at these sites.

We also showed by laboratory experiments with PSL particles that sea-salt aerosols caused $M_{\mathrm{BC}}$ (COSMOS) to be overestimated by about $2 \mathrm{ng} \mathrm{m}^{-3}$ on average under the conditions at Barrow and Ny-Ålesund. $M_{\mathrm{BC}}$ (COSMOS) derived by using MAC (COSMOS) obtained by our previous studies in Asia agreed to within 9\%, with an uncertainty of $17 \%$, with $M_{\mathrm{EC}}$ values measured by the thermal-optical transmittance technique at Barrow for 11 months (August 2012 to June 2013). Further, $M_{\mathrm{BC}}$ (COSMOS) values agreed to within 3\%, with an uncertainty of $15 \%$, with $M_{B C}$ measured by a single particle soot photometer (SP2) near Ny-Ålesund for 3 days in winter 2013 during the ACCACIA aircraft campaign. These results indicate that at both sites, $M_{\mathrm{BC}}$ (COSMOS) was consistent and reliable.

We found that $b_{\text {abs }}$ (PSAP) was highly correlated with $b_{\text {abs }}$ (COSMOS). The high correlations enabled reliable estimation of $M_{\mathrm{BC}}$ (PSAP) from $b_{\mathrm{abs}}$ (PSAP). $b_{\mathrm{abs}}$ (PSAP) was systematically higher than $b_{\mathrm{abs}}$ (COSMOS) by $22 \%$ at Barrow $\left(\mathrm{PM}_{1}\right)$ and by $43 \%$ at Ny-Ålesund $\left(\mathrm{PM}_{10}\right)$. The higher $b_{\mathrm{abs}}(\mathrm{PSAP})$ than $b_{\mathrm{abs}}(\mathrm{COSMOS})$ is attributable to enhanced absorption by internal mixing of $\mathrm{BC}$ and additional light absorption by volatile light-absorbing aerosol species.

At Barrow, monthly mean $M_{\mathrm{BC}}$ (COSMOS) averaged over 3 years agreed to within $10 \%$ with $M_{\mathrm{BC}}$ (PSAP) averaged over 10 years. At Ny-Ålesund, the 3 year monthly mean $M_{\mathrm{BC}}$ (COSMOS) values agreed with $M_{\mathrm{BC}}$ (PSAP) values averaged over 8 years to within 15\%. At Barrow, $M_{\mathrm{BC}}$ (COSMOS) reached a maximum of 38.4 $\pm 26.0 \mathrm{ng} \mathrm{m}^{-3}$ in winter and a minimum of $9.3 \pm 12.0 \mathrm{ng} \mathrm{m}^{-3}$ in summer. At Ny-Ålesund, $M_{\mathrm{BC}}$ (COSMOS) was $22.3 \pm 21.0 \mathrm{ng} \mathrm{m}^{-3}$ in winter and $6.2 \pm 7.9 \mathrm{ng} \mathrm{m}^{-3}$ in summer during 2012-2015.

We estimated the linear trend of $M_{\mathrm{BC}}$ (PSAP) values obtained at Barrow during 1998-2015 by linear regression and the Markov chain Monte Carlo methods. The seasonally averaged $M_{\mathrm{BC}}$ (PSAP) generally decreased in winter and summer at a rate of about $0.55 \pm 0.30 \mathrm{ng} \mathrm{m}^{-3} \mathrm{yr}^{-1}$. However, the absolute values of the rates are highly uncertain, partly owing to the large year-to-year variability of $M_{\mathrm{BC}}$ (PSAP) values.

At Ny-Ålesund, $M_{\mathrm{BC}}{ }^{*}$ (PSAP-PM ${ }_{10}$ ) values were systematically greater than $M_{\mathrm{BC}}$ (PSAP) values by a factor of 3.2 and 3.6 in winter and summer, respectively. $M_{\mathrm{BC}}$ (aethalometer) values were greater than $M_{\mathrm{BC}}$ (PSAP) values by a factor of 1.3 at Barrow in both winter and summer and of about 3.0 and 3.1 at Ny-Ålesund in winter and summer, respectively. We analyzed the causes of the inconsistency in the previously reported $M_{\mathrm{BC}}$ values in the Arctic.

The accuracy of $M_{\mathrm{BC}}$ (COSMOS) has been critically assessed by this study, and we anticipate that $M_{\mathrm{BC}}$ (COSMOS) will continue to be a reliable reference value for $M_{\mathrm{BC}}$ at Barrow and Ny-Ålesund in the Arctic. 


\section{Appendix A}

\section{A1. Measurements of $\boldsymbol{b}_{\mathrm{abs}}$ and $\boldsymbol{b}_{\mathrm{sca}}$ at Barrow and Ny-Ålesund}

In this Appendix, we describe the measurement method of $b_{\text {abs }}$ by using PSAP and CLAP at Barrow and NyÅlesund. The ambient air was aspirated at a flow rate of about $0.9 \mathrm{~L} \mathrm{~min}^{-1}$ at STP to measure $b_{\text {abs. }}$ Unlike the PSAP, the CLAP uses a solenoid valve to cycle through eight sample filter spots and two reference spots, which facilitates field observations, particularly in remote locations.

$b_{\text {sca }}$ at $\lambda=550 \mathrm{~nm}$ was measured with integrating nephelometers at Barrow $\left(\mathrm{PM}_{1}\right.$ and $\left.\mathrm{PM}_{10}\right)$ and Ny-Ålesund. Detailed descriptions of the measurements, instrument calibration, and uncertainty analysis are presented elsewhere [Anderson and Ogren, 1998; Anderson et al., 1999; Sheridan et al., 2001]. The overall uncertainty of $b_{\text {sca }}$ averaged over $1 \mathrm{~min}$, accounting for instrumental noise, drift in calibration, Rayleigh scattering of air, and blocking of near-forward scattering light (truncation), was less than 10\% [Sheridan et al., 2001]. The uncertainty of $b_{\text {abs }}$ (PSAP) was estimated to be about $20 \%$ for the $1 \mathrm{~h}$ average at midlatitudes $\left(35^{\circ} \mathrm{N}-45^{\circ} \mathrm{N}\right)$, taking account of instrumental noise, calibration of PSAP following Bond et al. [1999], and unit-to-unit variability [Sherman et al., 2015].

The PSAP and nephelometers at Barrow were equipped with switchable $\mathrm{PM}_{1}$ and $\mathrm{PM}_{10}$ impactors for particle size selection. The $\mathrm{PM}_{1}$ and $\mathrm{PM}_{10}$ size ranges were alternated every $30 \mathrm{~min}$ (twice each hour). We therefore used $b_{\text {abs }}$ values obtained by the PSAP during the last $30 \mathrm{~min}$ of each hour for the comparison with the COSMOS measurements at Barrow in this study. Data were further screened to avoid any local contamination; only data collected when the wind direction was from the clean air sector, from 0 to $130^{\circ}$, were included.

At Ny-Ålesund, measurements of $b_{\text {abs }}$ at $532 \mathrm{~nm}$ were also carried out at about $10 \mathrm{~m}$ above the ground by using a custom-built PSAP until November 2012. The custom-built PSAP was replaced with a new PSAP in December 2012. The $b_{\text {abs }}$ values obtained by the new PSAP were larger than those obtained by the custom-built PSAP by a factor of about 1.52 on average. The $b_{\text {abs }}$ (PSAP) data obtained after December 2012 were corrected for this bias. These $b_{\text {abs }}$ (PSAP) values were also adjusted to $550 \mathrm{~nm}$ as described in section 3.

\section{A2. Measurements of the Mass Concentration of Sea Salt at Barrow and Ny-Ålesund}

For measurement of the $M_{s-s}$ at Barrow, ambient air samples were collected onto filters after particle-size selection by $\mathrm{PM}_{1}$ and $\mathrm{PM}_{10}$ impactors through an inlet mounted $10 \mathrm{~m}$ above the ground from October 1997 to December 2009. The chemical composition of the collected aerosols, including $\mathrm{Na}^{+}$and $\mathrm{Cl}^{-}$, was analyzed by ion chromatography. Depending on the season and the aerosol loading, filter samples were collected at 1 to 4 day intervals at Barrow. Quinn et al. [2002] have described the sampling and measurement analysis at Barrow in detail. We estimated $M_{s-s}$ from the $\mathrm{Na}^{+}$concentration, and we also took into account the $\mathrm{Cl}^{-}$concentration to minimize the effect of the loss of $\mathrm{Cl}^{-}$owing to the release of $\mathrm{HCl}$ from the sea-salt aerosol. Other components such as sulfate that are not always present in sea-salt aerosols at the standard seawater ratio also add to the uncertainty in the estimation of $M_{s-s}$ with equation (7).

At Ny-Ålesund, ambient air samples containing sea-salt particles were collected daily from January 2012 to December 2014 as part of a cooperative program for monitoring and evaluation of long-range transmission of air pollutants in Europe (European Monitoring and Evaluation Programme) by using a filter pack sampler mounted $2 \mathrm{~m}$ above the ground. No impactor was used to restrict the size of the particles for $M_{s-s}$ measurement at Ny-Ålesund, but for simplicity, we refer to these data as $\mathrm{PM}_{10}$ in our comparison, despite the fact that the resulting $M_{s-s}$ values might be larger than $M_{s-s}\left(\mathrm{PM}_{10}\right)$ values.

Hjellbrekke and Fjæraa [2009] have described the detailed sample collection and analysis procedures. $M_{s-s}$ in the submicrometer size range at Ny-Ålesund was deduced by assuming the value of $f_{\mathrm{PM} 1}\left(=\mathrm{PM}_{1} / \mathrm{PM}_{10}\right.$ ratio $)$ of $M_{s-s}$ measured at Barrow. At Barrow, $f_{\mathrm{PM} 1}$ varied between 0.08 and 0.77 during 1997-2009. The use of the measured values of $M_{s-s}$ may result in the overestimation of $M_{s-s}\left(\mathrm{PM}_{1}\right)$ at $\mathrm{Ny}$-Ålesund. Such overestimation would have little influence on the conclusion derived from this analysis, however.

\section{A3. Measurements of $M_{\mathrm{EC}}$ at Barrow}

The samples were collected outdoors on a sampling platform $10 \mathrm{~m}$ above ground level at the North Slope of Alaska Atmospheric Radiation Measurement Facility at Barrow. Filters were heated to $500^{\circ} \mathrm{C}$ for $12 \mathrm{~h}$ prior to 

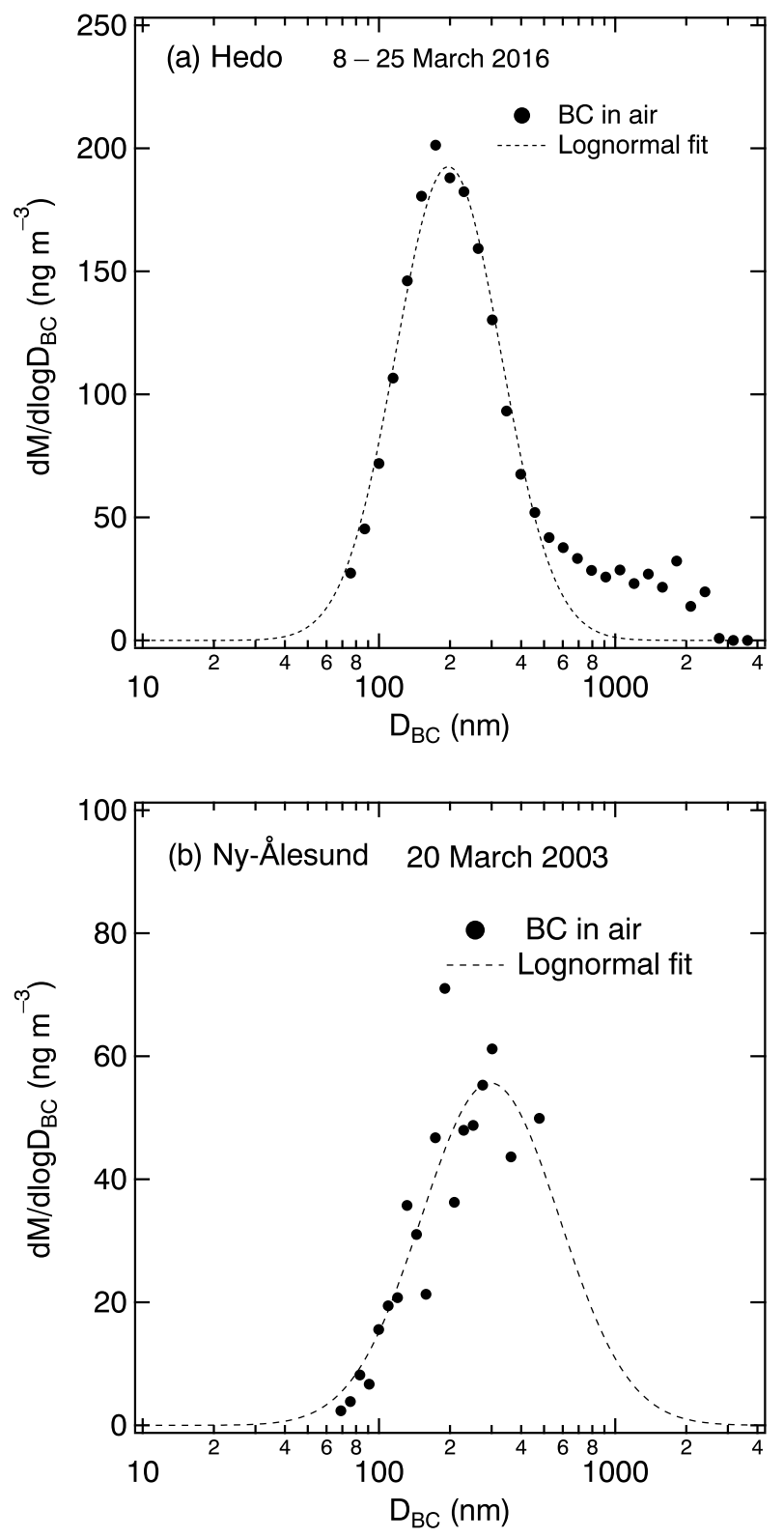

Figure A1. (a) Mean mass size distribution of BC particles measured by SP2 between 8 and 25 March 2016 at Hedo, Okinawa. The dashed line shows the fitted lognormal function. (b) Same as Figure A1a but of airborne SP2 measurements made near Zeppelin station, Ny-Ålesund, on 20 March 2013, during the ACCACIA campaign.

the $\mathrm{BC}$ mass size distribution measured by an SP2 at the remote site of Hedo $\left(26.9^{\circ} \mathrm{N}, 128.3^{\circ} \mathrm{E}\right)$ on Okinawa Island, Japan, during 17 days in March 2016 (Figure A1a). Hedo is located downstream of China [Kondo et al., 2011c]. BC mass concentrations below the detection limit of the SP2 (around $75 \mathrm{~nm}$ ) were estimated by extrapolating a lognormal function fitted to the $\mathrm{BC}$ mass size distribution. Mean $M_{\mathrm{BC}}$ was $128.8 \mathrm{ng} \mathrm{m}^{-3}$ between 0 and $4000 \mathrm{~nm}\left(\mathrm{PM}_{4}\right)$ and $10.0 \mathrm{ng} \mathrm{m}^{-3}$ between 1000 and $4000 \mathrm{~nm}$. On average, the ratio of $M_{\mathrm{BC}}$ above $1 \mu \mathrm{m}$ in diameter to total $M_{\mathrm{BC}}$ was $0.08(8 \%)$.

\section{Ny-Ålesund}

The BC mass size distribution in airborne SP2 measurements at an altitude of about $500 \mathrm{~m}$ near Zeppelin station, Ny-Ålesund, on 20 March 2013, is shown in Figure A1b. BC mass concentrations above the 


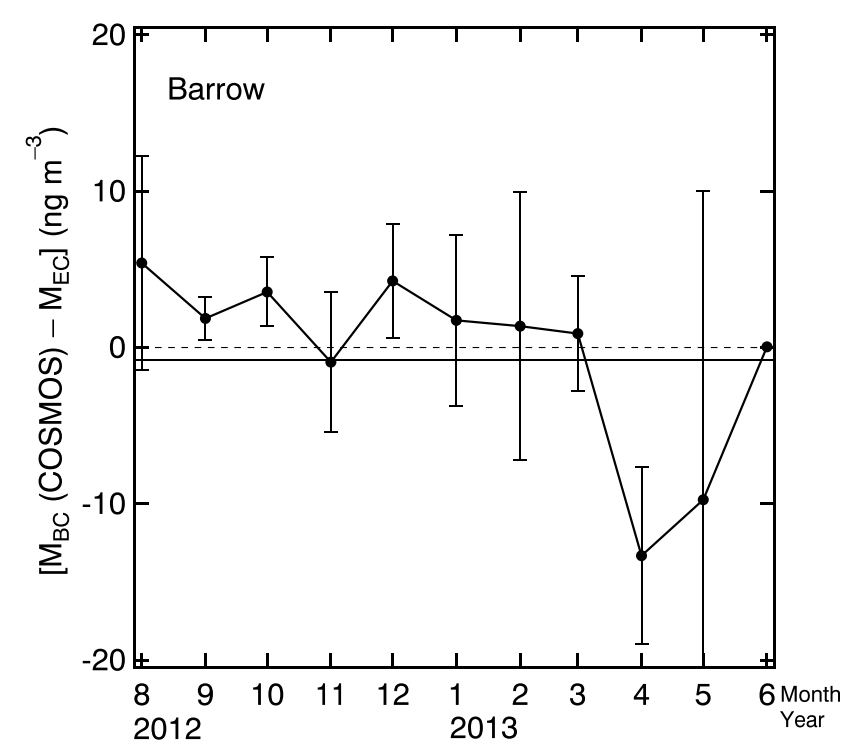

Figure A2. Time series of the difference between the monthly mean values of $M_{\mathrm{BC}}$ (COSMOS) and $M_{\mathrm{EC}}$ at Barrow from August 2012 to June 2013. The vertical bars represent the standard deviations $( \pm 1 \sigma)$ of the monthly mean values, and the annual mean value is shown by the dashed horizontal line.

detection range of the SP2 measurements of $477 \mathrm{~nm}$ were estimated from a lognormal function fitted to the $\mathrm{BC}$ mass size distribution up to $1000 \mathrm{~nm}$. The contributions of $\mathrm{BC}$ mass concentrations between $478 \mathrm{~nm}$ and $1000 \mathrm{~nm}$ to $M_{\mathrm{BC}}(\mathrm{SP} 2)$ for $\mathrm{PM}_{1}$ were estimated to be in the range of $8.7-17.7 \%$ between 20 and 23 March 2013 with a mean contribution of about $15 \%$.

\section{A5. Seasonal Variation of the Difference Between $M_{\mathrm{BC}}$ (COSMOS) and $M_{\mathrm{EC}}$ at Barrow}

Figure $\mathrm{A} 2$ presents the monthly mean values of the difference between $M_{\mathrm{BC}}$ (COSMOS) and $M_{\mathrm{EC}}$ at Barrow from August 2012 to June 2013. The $M_{\mathrm{BC}}$ (COSMOS)- $M_{\mathrm{EC}}$ difference was generally lower than $5 \mathrm{ng} \mathrm{m}^{-3}$ for most months except April and May 2013. However, no distinct seasonal variation in the monthly mean difference

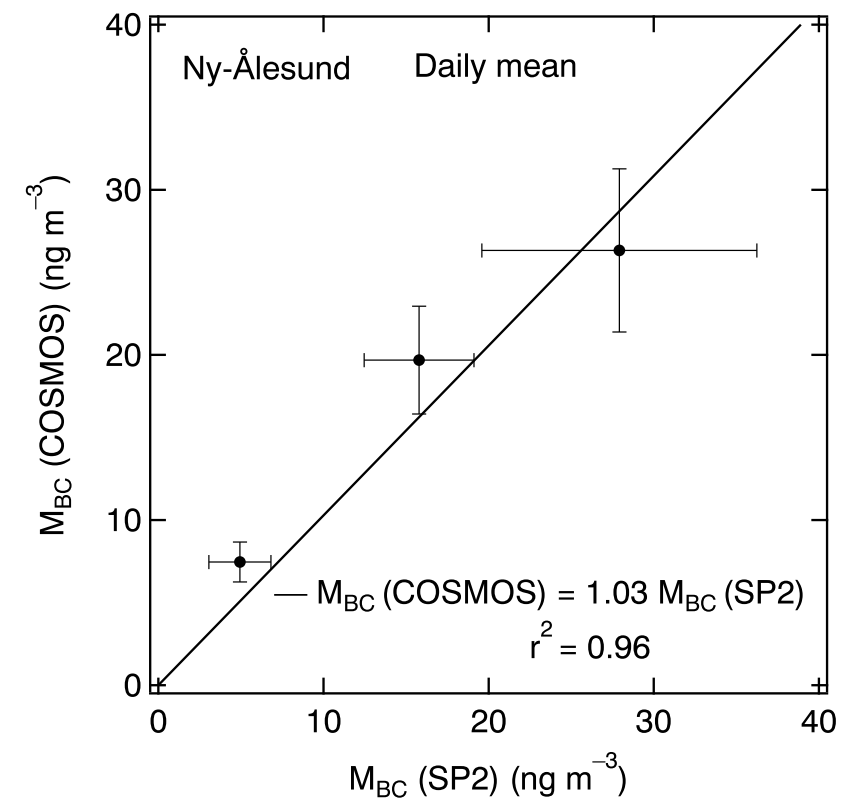

Figure A3. Correlation between daily mean $M_{\mathrm{BC}}$ (COSMOS) and $M_{\mathrm{BC}}$ (SP2) values measured during the ACCACIA campaign near Ny-Ålesund. between $M_{\mathrm{BC}}$ (COSMOS) and $M_{\mathrm{EC}}$ is apparent.

A6. Comparison of $M_{\mathrm{BC}}$ (COSMOS) and $M_{\mathrm{BC}}$ (SP2) at Ny-Ålesund

We compared the daily mean $M_{\mathrm{BC}}$ (COSMOS) with $M_{\mathrm{BC}}$ (SP2) values linearly interpolated to $474 \mathrm{~m}$ altitude and present the results in Figure A3. The daily mean $M_{\mathrm{BC}}$ (COSMOS) and $M_{\mathrm{BC}}$ (SP2) agreed to within about $3 \%$ (slope $\left.=1.03, r^{2}=0.96\right)$ with an uncertainty of about $15 \%$, although the statistical reliability is limited owing to the small number of $M_{\mathrm{BC}}$ (SP2) measurements.

A7. Daily and Monthly Variations of the Single Scattering Albedo at Barrow and Ny-Ålesund

Time series plots of daily and monthly mean variations of the single scattering albedo (SSA) from 

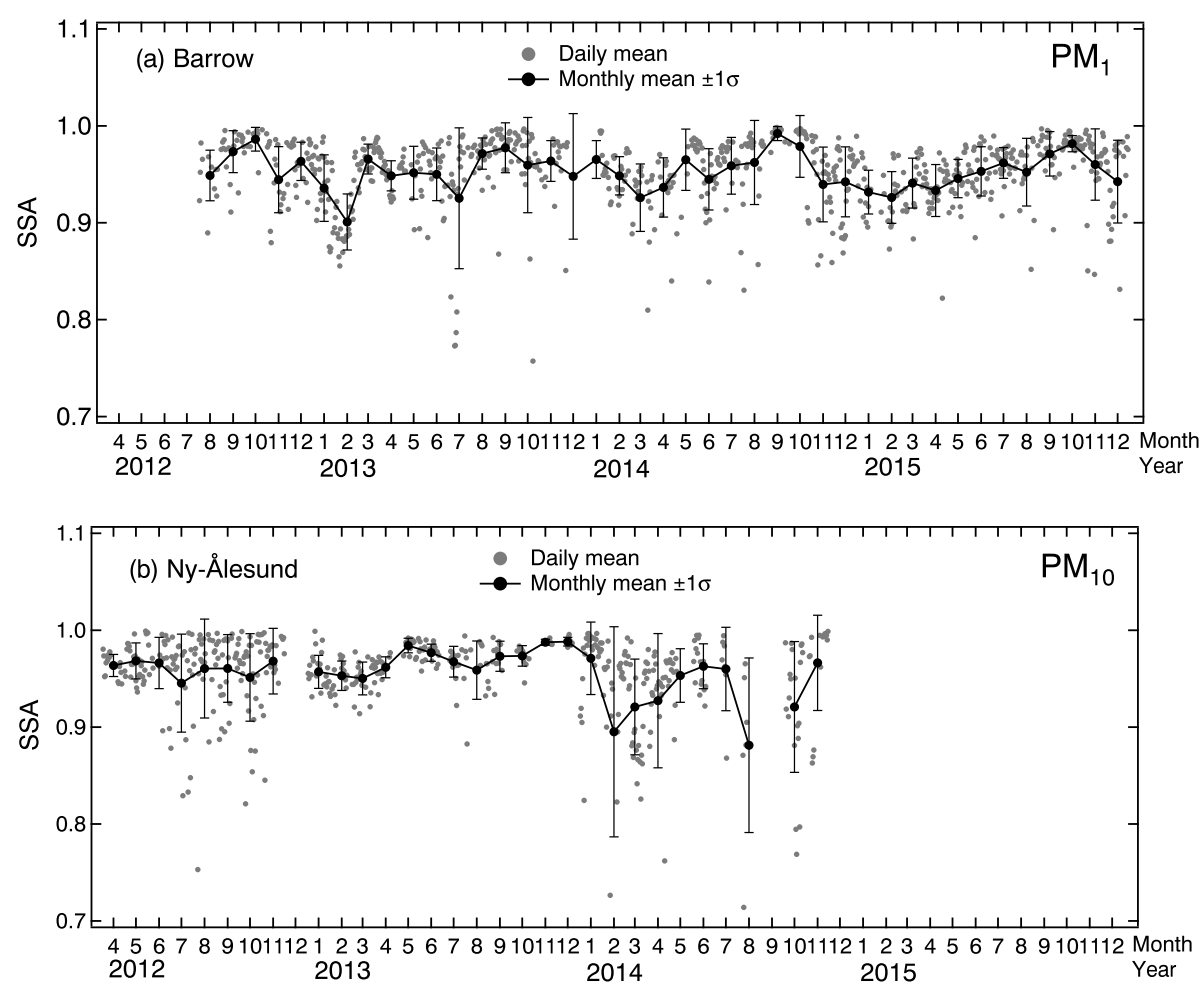

Figure A4. (a) Daily and monthly mean values of single scattering albedo (SSA) for $\mathrm{PM}_{1}$ at Barrow from 2012 to 2015. (b) Same as Figure A4a but at Ny-Ålesund for $\mathrm{PM}_{10}$ during 2012-2014.

hourly data at Barrow $\left(\mathrm{PM}_{1}\right)$ and Ny-Ålesund $\left(\mathrm{PM}_{10}\right)$ are shown Figure A4. At Barrow, SSA showed considerable day-to-day variability, particularly during winter, whereas at Ny-Ålesund, conspicuous variability was not seen, although episodically low SSA values were observed there in both winter and summer.

The amplitude of the seasonal variation of SSA was stronger at Barrow than at Ny-Ålesund. At Barrow, the mean wintertime SSA value $(0.94 \pm 0.03)$ in winter was lower than the summertime mean $(0.96 \pm 0.04)$. This wintertime SSA value is very similar to the value of 0.94 derived by Delene and Ogren [2002] for March-May during 1997-2000. At Ny-Ålesund, the mean wintertime SSA value of $0.95 \pm 0.05$ was higher than the wintertime mean at Barrow, but the summertime mean $(0.96 \pm 0.04)$ was similar to that at Barrow.

\section{A8. Comparison of $M_{\mathrm{BC}}$ (COSMOS) and $M_{\mathrm{BC}}$ (PSAP) at Barrow and $\mathrm{Ny}$-Ålesund}

\section{A8.1. Difference Between Monthly Mean $M_{\mathrm{BC}}$ (COSMOS) and $M_{\mathrm{BC}}$ (PSAP)}

Time series of the difference between monthly mean $M_{\mathrm{BC}}$ (COSMOS) and $M_{\mathrm{BC}}$ (PSAP) at Barrow (2012-2015) and at Ny-Ålesund (2012-2014) are presented in Figure A5. Although this difference, $M_{\mathrm{BC}}(\mathrm{COSMOS})-M_{\mathrm{BC}}$ (PSAP), varied greatly from year to year, the variation was not systematic at these sites during the study period. The difference was generally less than $10 \mathrm{ng} \mathrm{m}^{-3}$ at both sites, and the standard deviation of the difference was about $4.7 \mathrm{ng} \mathrm{m}^{-3}$ at Barrow and $3.8 \mathrm{ng} \mathrm{m}^{-3}$ at Ny-Ålesund. The maximum year-to-year variability of MAC (PSAP) was about $\pm 20 \%$ at Barrow. This value is a measure of the year-to-year stability of the $M_{\mathrm{BC}}$ (PSAP) measurements in the Arctic and partly accounts for the difference between the monthly mean values of $M_{\mathrm{BC}}(\mathrm{COSMOS})$ and $M_{\mathrm{BC}}$ (PSAP).

\section{A8.2. Scatterplot of Monthly Mean $M_{\mathrm{BC}}$ (COSMOS) and $M_{\mathrm{BC}}$ (PSAP)}

We examined the correlation between monthly mean $M_{\mathrm{BC}}$ (COSMOS) and $M_{\mathrm{BC}}$ (PSAP) values at Barrow and Ny-Ålesund to visualize the degree to which individual data points deviated from the average correlation, 

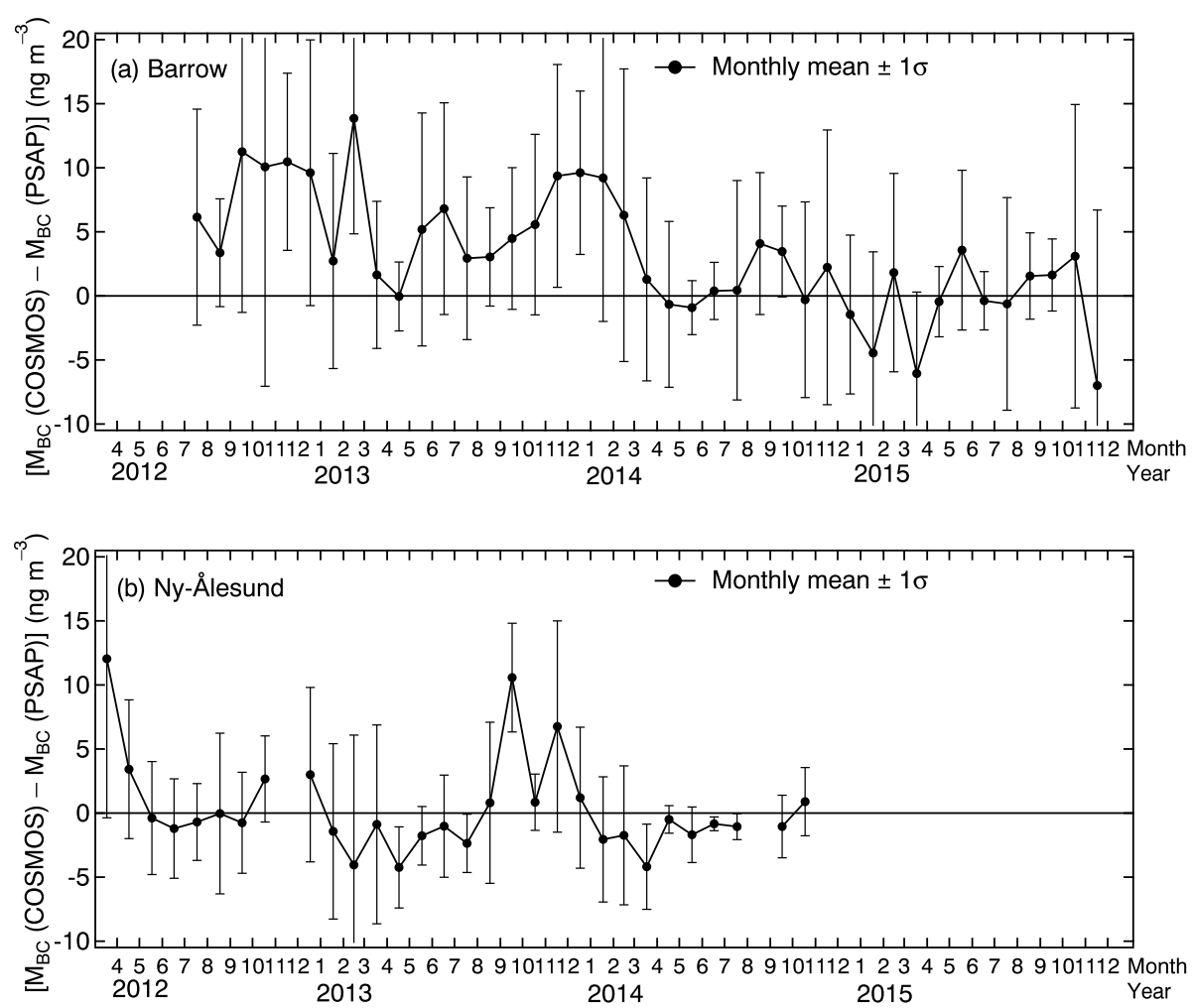

Figure A5. (a) Time series of the difference between monthly mean values of $M_{\mathrm{BC}}$ (COSMOS) and $M_{\mathrm{BC}}$ (PSAP) at Barrow during 2012-2015. The vertical bars represent the standard deviations $( \pm 1 \sigma)$ of the monthly mean values. (b) Same as Figure A5a but at Ny-Ålesund for $\mathrm{PM}_{10}$ during 2012-2014.

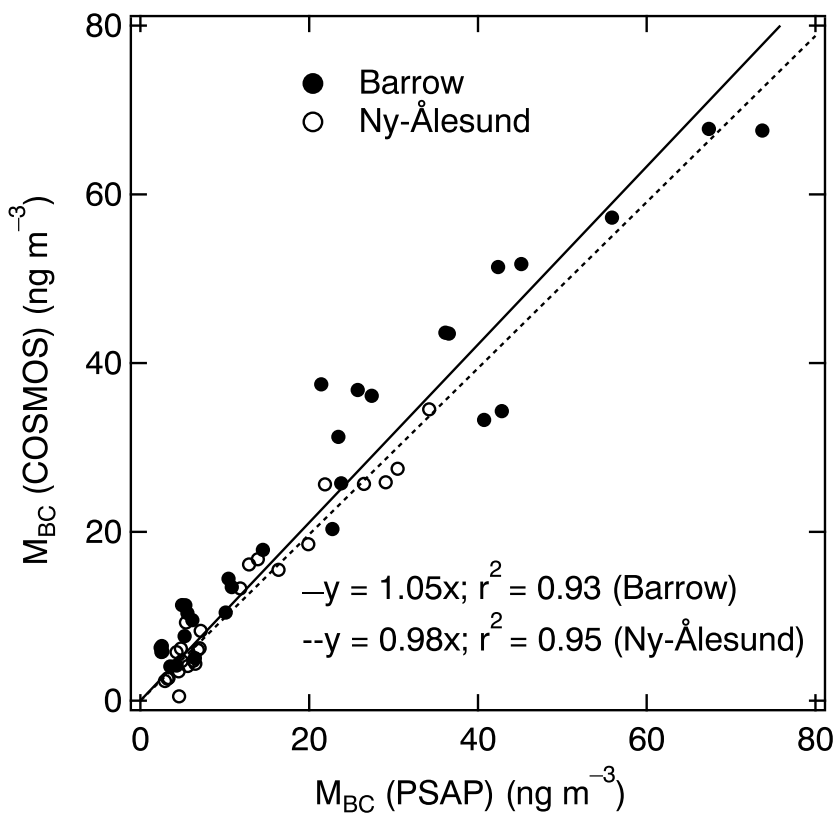

Figure A6. Correlations between monthly mean $M_{\mathrm{BC}}$ (COSMOS) and $M_{\mathrm{BC}}$ (PSAP) values at Barrow and Ny-Ålesund. We excluded the monthly means of $M_{\mathrm{BC}}$ (COSMOS) and $M_{\mathrm{BC}}$ (PSAP) for months with less than 17 daily data points. 

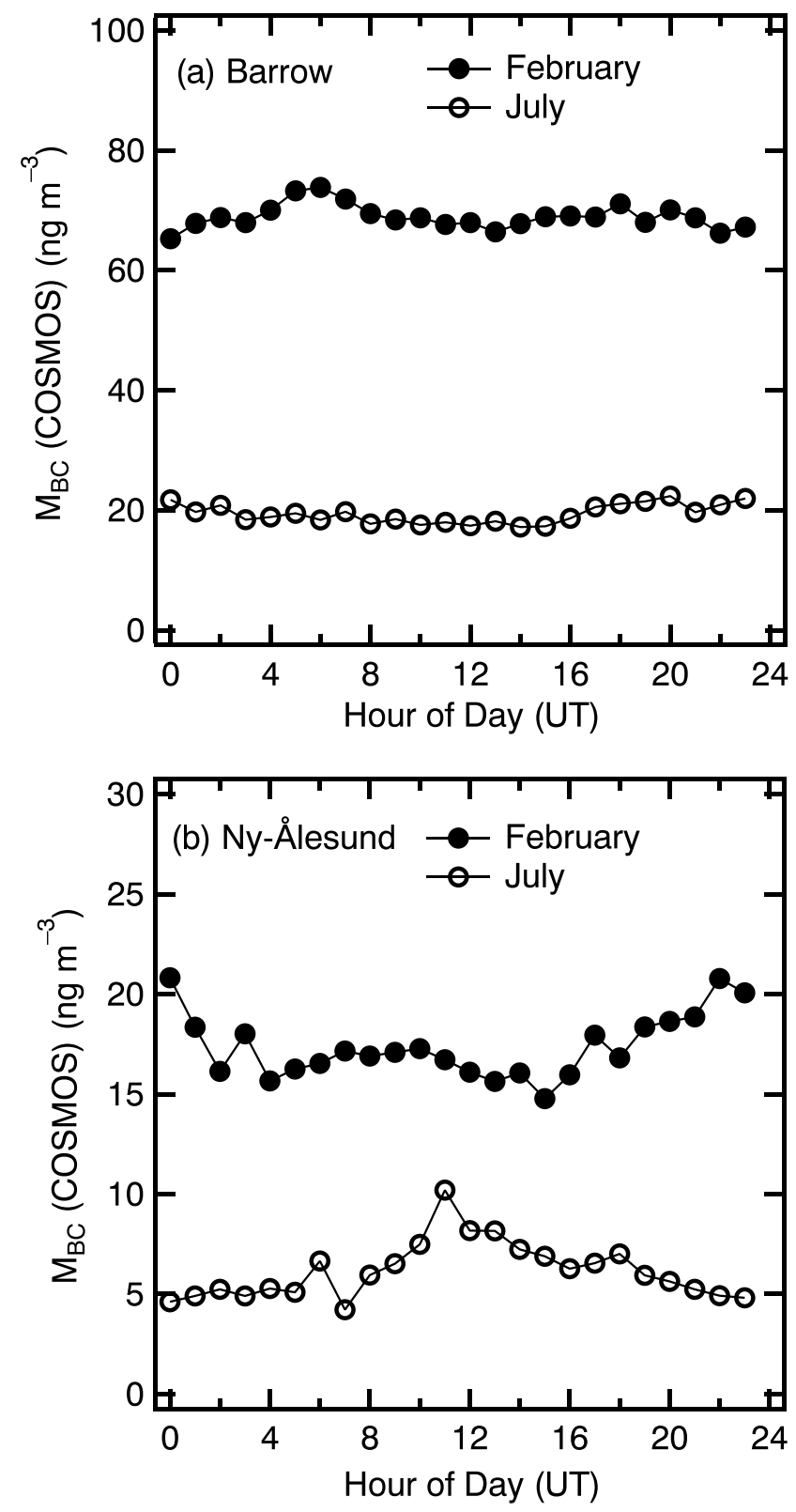

Figure A7. Diurnal variations of $M_{\mathrm{BC}}$ (COSMOS) values averaged over February and July 2013 at (a) Barrow and (b) Ny-Ålesund. as shown in Figure A6. Monthly mean $M_{\mathrm{BC}}$ (COSMOS) and $M_{\mathrm{BC}}$ (PSAP) values were well correlated $\left(r^{2}=0.96\right.$ at Barrow and 0.95 at Ny-Ålesund), as expected given the correlations between $b_{\mathrm{abs}}$ (PSAP) and $b_{\mathrm{abs}}$ (COSMOS). The average slope was 1.05 at Barrow and 0.98 at $\mathrm{Ny}$ Ålesund, as a result of the scaling.

\section{A9. Diurnal Variation of $M_{\mathrm{BC}}$ at Barrow and Ny-Ålesund}

Monthly mean diurnal variations of $M_{\mathrm{BC}}$ (COSMOS) at Barrow and $\mathrm{Ny}$ Ålesund in February and July 2013 are shown in Figure A7. These months were chosen as representative of the winter and summer seasons, respectively. At both sites, the amplitude of the diurnal variation in $M_{\mathrm{BC}}$ (COSMOS) was generally smaller in July than in February, partly reflecting the seasonal variation in $M_{\mathrm{BC}}$ (COSMOS). Overall, the monthly mean diurnal variation of $M_{\mathrm{BC}}$ (COSMOS) was generally less than $10 \%$ of the daily mean in all months. Similarly, Sharma et al. [2002] and Eleftheriadis et al. [2009] reported weak diurnal variability in $M_{\mathrm{BC}}$ at Ny-Ålesund. The absence of diurnal variability in $M_{\mathrm{BC}}$ (COSMOS) suggests that the influence of localized BC emissions on the measured $M_{\mathrm{BC}}$ was small; however, anthropogenic activities have been observed to vary diurnally in more populated areas [e.g., Sahu et al., 2011]. In addition, if very high concentrations of $B C$ are confined within the relatively shallow atmosphere near

Table A1. Trends of Seasonally Averaged $M_{\mathrm{BC}}$ (PSAP) Between 1998 and 2015 at Barrow ${ }^{\mathrm{a}}$

\begin{tabular}{|c|c|c|c|}
\hline \multicolumn{2}{|c|}{ Markov Chain Monte Carlo Method } & \multicolumn{2}{|c|}{ Least-Squares Fit } \\
\hline Month & Slope $\left(\mathrm{ng} \mathrm{m}^{-3} \mathrm{yr}^{-1}\right) \pm 1 \sigma$ & Slope $\left(\mathrm{ng} \mathrm{m}^{-3} \mathrm{yr}^{-1}\right) \pm 1 \sigma$ & $r^{2}$ \\
\hline December-February & $-1.04 \pm 0.64$ & $-1.04 \pm 0.75$ & 0.11 \\
\hline March-May & $-0.94 \pm 0.79$ & $-0.37 \pm 0.38$ & 0.06 \\
\hline June-August & $-0.43 \pm 0.27$ & $-0.41 \pm 0.19$ & 0.24 \\
\hline September-November & $-0.44 \pm 0.29$ & $-0.55 \pm 0.16$ & 0.43 \\
\hline
\end{tabular}

${ }^{\mathrm{a}}$ The linear trends and their standard deviations $( \pm 1 \sigma)$ were estimated by a regression analysis performed by using the Markov chain Monte Carlo method. The linear trends estimated by least squares fitting are also shown, together with their $\pm 1 \sigma$ and $r^{2}$ values. 

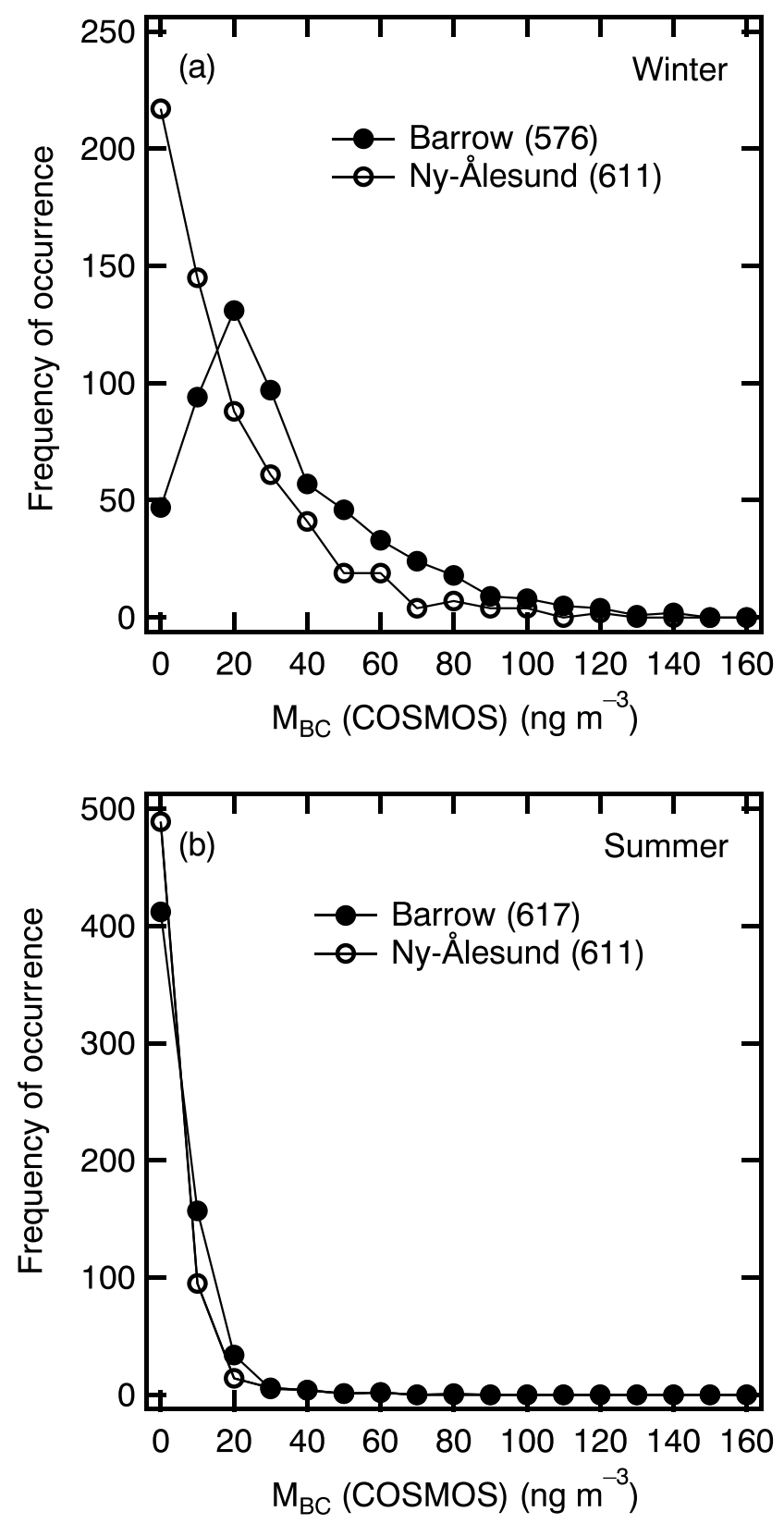

Figure A8. Frequency distributions of daily mean $M_{\mathrm{BC}}$ (COSMOS) at Barrow and $\mathrm{Ny}$-Ålesund in (a) winter (November-April) and (b) summer (MayOctober) from 2012 to 2015 . The number of data points in each season at each site is shown in parentheses.

sented in Figure A8. During winter, values of $M_{B C}$ (COSMOS) of $20-30 \mathrm{ng} \mathrm{m}^{-3}$ were more frequent at Barrow than at Ny-Ålesund, where the distribution was shifted to lower $M_{B C}$ (COSMOS) values. The frequency distributions of $M_{\mathrm{BC}}$ (COSMOS) at the two sites had long thin tails, which extended to more than $100 \mathrm{ng} \mathrm{m}^{-3}$, in winter. During summer, the frequency distributions of $M_{\mathrm{BC}}$ (COSMOS) were similar at the two sites. The $M_{\mathrm{BC}}$ (COSMOS) distribution was skewed toward lower values, with a mode at $5 \mathrm{ng} \mathrm{m}^{-3}$, indicating more frequent occurrence of low $\mathrm{BC}$ loadings. The frequency distributions of $M_{\mathrm{BC}}$ (COSMOS) were much narrower at lower $M_{\mathrm{BC}}$ values in summer compared with those in winter. The seasonal variation in $M_{\mathrm{BC}}$ (COSMOS) is mainly attributable to changes in transport pathways and the degree of wet deposition of $\mathrm{BC}$ during transport. It is often 
difficult for transport models to predict precisely trajectories of individual air parcels reaching the observation sites at given times. Comparison of the occurrence frequencies observed by this study and those calculated by numerical models would be useful for statistical evaluation of the transport processes included in the models. Such a comparison was made for Asia by Kondo et al. [2011c].

\section{Acknowledgments}

We thank NOAA personnel for reliably carrying out the observations by PSAP, nephelometer, and COSMOS instruments at Barrow. We also thank the staff of the Norwegian Polar Institute for reliably performing the COSMOS measurements at Zeppelin station, $\mathrm{Ny}$ Ålesund. This work was supported by the Ministry of Education, Culture, Sports, Science, and Technology (MEXT), the Global Environment Research Fund of the Japanese Ministry of the Environment (A-1101, 2-1403, and 21703), the Japan Society for the Promotion of Science (JSPS) KAKENHI grants (JP12J06736, JP23221001, and JP16H01770), the GRENE Arctic Climate Change Research Project, and the Arctic Challenge for Sustainability (ArCS) project. This is Pacific Marine

Environmental Laboratory (PMEL) contribution number 4552 . We thank the anonymous reviewers for their constructive comments and suggestions. The data used in this study are available upon request from the authors. (kondo. yutaka@nipr.ac.jp).

\section{References}

Anderson, T. L., and J. A. Ogren (1998), Determining aerosol radiative properties using the TSI 3563 integrating nephelometer, Aerosol Sci. Technol., 29, 57-69.

Anderson, T. L., D. S. Covert, J. D. Wheeler, J. M. Harris, K. D. Perry, B. E. Trost, D. J. Jaffe, and J. A. Ogren (1999), Aerosol backscatter fraction and single scattering albedo: Measured values and uncertainties at a coastal station in the Pacific Northwest, J. Geophys. Res., 104(D21), 26,793-26,807, doi:10.1029/1999JD900172.

Barrett, T. E., E. M. Robinson, S. Usenko, and R. J. Sheesley (2015), Source contributions to wintertime elemental and organic carbon in the western Arctic based on radiocarbon and tracer apportionment, Environ. Sci. Technol., 49, 11,631-11,639.

Barrie, L. A., and M. J. Barrie (1990), Chemical components of lower tropospheric aerosols in the high Arctic: Six years of observations, J. Atmos. Chem., 11, 211-226.

Birch, M. E., and R. A. Cary (1996), Elemental carbon-based method for monitoring occupational exposures to particulate diesel exhaust, Aerosol Sci. Technol., 25, 221-241.

Bodhaine, B. A. (1995), Aerosol absorption measurements at Barrow, Mauna Loa and the south pole, J. Geophys. Res., 100(D5), 8967-8975, doi:10.1029/95JD00513.

Bond, T. C., T. L. Anderson, and D. Campbell (1999), Calibration and inter-comparison of filter based measurements of visible light absorption by aerosols, Aerosol Sci. Technol., 30, 582-600.

Bond, T. C., et al. (2013), Bounding the role of black carbon in the climate system: A scientific assessment, J. Geophys. Res. Atmos., 118, 5380-5552, doi:10.1002/jgrd.50171.

Brock, C. A., et al. (2011), Characteristics, sources, and transport of aerosols measured in spring 2008 during the Aerosol, Radiation, and Cloud Processes Affecting Arctic Climate (ARCPAC) project, Atmos. Chem. Phys., 11, 2423-2453.

Browse, J., K. S. Carslaw, S. Arnold, K. J. Pringle, and O. Boucher (2012), The scavenging processes controlling the seasonal cycle in Arctic sulphate and black carbon aerosol, Atmos. Chem. Phys., 12, 6775-6798.

Collaud Coen, M., et al. (2013), Aerosol decadal trends-Part 1: In-situ optical measurements at GAW and IMPROVE stations, Atmos. Chem. Phys., 13, 869-894.

Delene, D. J., and J. A. Ogren (2002), Variability of aerosol optical properties at four North American surface monitoring sites, J. Atmos. Sci., 59, 1135-1150.

Eleftheriadis, K., S. Vratolis, and S. Nyeki (2009), Aerosol black carbon in the European Arctic: Measurements at Zeppelin station, Ny-Ålesund, Svalbard from 1998-2007, Geophys. Res. Lett., 36, L02809, doi:10.1029/2008GL035741.

Flanner, M. G., C. S. Zender, J. T. Randerson, and P. J. Rasch (2007), Present day climate forcing and response from black carbon in snow, J. Geophys. Res., 112, D11202, doi:10.1029/2006JD008003.

Hirdman, D., H. Sodemann, S. Eckhardt, J. F. Burkhart, A. Jefferson, T. Mefford, P. K. Quinn, S. Sharma, J. Ström, and A. Stohl (2010a), Source identification of short-lived air pollutants in the Arctic using statistical analysis of measurement data and particle dispersion model output, Atmos. Chem. Phys., 10, 669-693.

Hirdman, D., J. F. Burkhart, H. Sodemann, S. Eckhardt, A. Jefferson, P. K. Quinn, S. Sharma, J. Ström, and A. Stohl (2010b), Long-term trends of black carbon and sulphate aerosol in the Arctic: Changes in atmospheric transport and source region emissions, Atmos. Chem. Phys., 10, 9351-9368.

Hjellbrekke, A.-G., and A. M. Fjæraa (2009), Data Report 2007: Acidifying and Eutrophying Compounds and Particulate Matter, EMEP/CCC Report 1/2009, Norwegian Institute for Air Research, Kjeller, Norway.

Hoff, P. D. (2009), A First Course in Bayesian Statistical Methods, pp. 270, Springer, London.

Holland, H. D. (1978), The Chemistry of the Atmosphere and Oceans, pp. 369, John Wiley, New York.

Irwin, M., Y. Kondo, N. Moteki, and T. Miyakawa (2013), Evaluation of a heated-inlet for calibration of the SP2, Aerosol Sci. Technol., 47, 895-905.

Kondo, Y. K. (2015), Effects of black carbon on climate: Advances in measurement and modeling, Monogr. Environ. Earth Planets, 3, 1-85.

Kondo, Y., et al. (2009), Stabilization of the mass absorption cross section of black carbon for filter-based absorption photometry by the use of a heated inlet, Aerosol Sci. Technol., 43, 741-756.

Kondo, Y., et al. (2011a), Emissions of black carbon, organic, and inorganic aerosols from biomass burning in North America and Asia in 2008 , J. Geophys. Res., 116, D08204, doi:10.1029/2010JD015152.

Kondo, Y., L. Sahu, N. Moteki, F. Khan, N. Takegawa, X. Liu, M. Koike, and T. Miyakawa (2011b), Consistency and traceability of black carbon measurements made by laser-induced incandescence, thermal-optical transmittance, and filter-based photo-absorption techniques, Aerosol Sci. Technol., 45, 295-312.

Kondo, Y., N. Oshima, M. Kajino, R. Mikami, N. Moteki, N. Takegawa, R. L. Verma, Y. Kajii, S. Kato, and A. Takami (2011c), Emissions of black carbon in East Asia estimated from the observations at a remote site in the East China Sea, J. Geophys. Res., 116, D16291, doi:10.1029/ 2011JD015637.

Kondo, Y., N. Moteki, S. Ohata, N. Oshima, M. Koike, Y. Shibano, N. Takegawa, and K. Kita (2016), Effects of wet deposition on the abundance and size distribution of black carbon in East Asia, J. Geophys. Res. Atmos., 121, 4961-4712, doi:10.1002/2015JD024479.

Krecl, P., J. Ström, and C. Johansson (2007), Carbon content of atmospheric aerosols in a residential area during the wood combustion season in Sweden, Atmos. Environ., 41, 6974-6985.

Lack, D. A., H. Moosmüller, G. R. McMeeking, R. K. Chakrabarty, and D. Baumgardner (2014), Characterizing elemental, equivalent black, and refractory black carbon aerosol particles: A review of techniques, their limitations and uncertainties, Anal. Bioanal. Chem., 406, 99-122, doi:10.1007/s00216-013-7402-3.

Liu, D., et al. (2010), Single particle characterization of black carbon aerosols at a tropospheric alpine site in Switzerland, Atmos. Chem. Phys., 10, 7389-7407.

Liu, D., et al. (2015), The importance of Asia as a source of black carbon to the European Arctic during springtime 2013, Atmos. Chem. Phys., $15,11,537-11,555$. 
Liu, J., S. Fan, L. Horowitz, and H. Levy (2011), Evaluation of factors controlling long-range transport of black carbon to the Arctic, J. Geophys. Res., 116, D04307, doi:10.1029/2010JD015145.

Matsui, H., et al. (2011), Seasonal variation of the transport of black carbon aerosol from the Asian continent to the Arctic during the ARCTAS aircraft campaign, J. Geophys. Res., 116, D05202, doi:10.1029/2010JD015067.

McMeeking, G. R., et al. (2010), Black carbon measurements in the boundary layer over western and northern Europe, Atmos. Chem. Phys., 10, 9393-9414.

McNaughton, C. S., et al. (2011), Absorbing aerosol in the troposphere of the western Arctic during the 2008 ARCTAS/ARCPAC airborne field campaigns, Atmos. Chem. Phys., 11, 7561-7582.

Miyakawa, T., N. Oshima, F. Taketani, Y. Komazaki, A. Yoshino, A. Takami, Y. Kondo, and Y. Kanaya (2016), Alteration of the microphysical properties of black carbon through transport in the boundary layer in East Asia, Atmos. Chem. Phys. Discuss., doi:10.5194/acp-2016-570.

Miyazaki, Y., Y. Kondo, L. K. Sahu, J. Imaru, N. Fukushima, and A. Kanno (2008), Performance of a newly designed continuous soot monitoring system (COSMOS), J. Environ. Monit., 10, 1195-1201.

Moteki, N., and Y. Kondo (2008), Method to measure time-dependent scattering cross-section of particles evaporating in a laser beam, J. Aerosol Sci., 39, 348-364.

Moteki, N., and Y. Kondo (2010), Dependence of laser-induced incandescence on physical properties of black carbon aerosols: Measurements and theoretical interpretation, Aerosol Sci. Technol., 44, 663-675.

Moteki, N., Y. Kondo, T. Nakayama, K. Kita, L. K. Sahu, T. Ishigai, T. Kinase, and Y. Matsumi (2010), Radiative transfer modeling of filterbased measurements of light absorption by particles: Importance of particle size dependent penetration depth, J. Aerosol Sci., 41, 401-412.

Moteki, N., Y. Kondo, N. Oshima N. Takegawa, M. Koike, K. Kita, H. Matsui, and M. Kajino (2012), Size dependence of wet removal of black carbon aerosols during transport from the boundary layer to the free troposphere, Geophys. Res. Lett., 39, L13802, doi:10.1029/ 2012GL052034.

Ogren, J. A. (2010), Comments on "Calibration and inter-comparison of filter-based measurements of visible light absorption by aerosols", Aerosol Sci. Technol., 44, 589-591.

Ohata, S., J. P. Schwarz, N. Moteki, M. Koike, A. Takami, and Y. Kondo (2016), Hygroscopicity of materials internally mixed with black carbon measured in Tokyo, J. Geophys. Res. Atmos., 121, 362-381, doi:10.1002/2015JD024153.

Petzold, A., et al. (2013), Recommendations for reporting "black carbon" measurements, Atmos. Chem. Phys., 13, 8365-8379.

Quinn, P. K., T. L. Miller, T. S. Bates, J. A. Ogren, E. Andrews, and G. E. Shaw (2002), A 3-year record of simultaneously measured aerosol chemical and optical properties at Barrow, Alaska, J. Geophys. Res., 107(D11), 4130, doi:10.1029/2001JD001248.

Quinn, P. K., G. E. Shaw, E. Andrews, E. G. Dutton, T. Ruoho-Airola, and S. L. Gong (2007), Arctic haze: Current trends and knowledge gaps, Tellus $B, 59,99-114$

Sahu, L. K., Y. Kondo, Y. Miyazaki, N. T. Kim Oanh, and P. Pongkiatkul (2011), Seasonal and diurnal variations of black carbon and organic carbon aerosols in Bangkok, J. Geophys. Res., 116, D15302, doi:10.1029/2010JD015563.

Sahu, L. K., et al. (2012), Emission characteristics of black carbon in anthropogenic and biomass burning plumes over California during ARCTAS-CARB 2008, J. Geophys. Res., 117, D16302, doi:10.1029/2011JD017401.

Sand, M., T. K. Berntsen, K. von Salzen, M. G. Flanner, J. Langner, and D. G. Victor (2016), Response of Arctic temperature to changes in emissions of short-lived climate forcers, Nat. Clim. Change, 6, 286-289.

Schwarz, J. P., et al. (2006), Single-particle measurement of mid latitude black carbon and light-scattering aerosols from the boundary layer to the lower stratosphere, J. Geophys. Res., 111, D16207, doi:10.1029/2006JD007076.

Schwarz, J. P., R. S. Gao, A. E. Perring, J. R. Spackman, and D. W. Fahey (2013), Black carbon aerosol size in snow, Sci. Rep., 3, 1356, doi:10.1038/ srep01356.

Sharma, S., J. R. Brook, H. Cachier, J. Chow, A. Gaudenzi, and G. Lu (2002), Light absorption and thermal measurements of black carbon in different regions of Canada, J. Geophys. Res., 107(D24), 4771, doi:10.1029/2002JD002496.

Sharma, S., M. Ishizawa, D. Chan, D. Lavoué, E. Andrews, K. Eleftheriadis, and S. Maksyutov (2013), 16-year simulation of Arctic black carbon: Transport, source contribution, and sensitivity analysis on deposition, J. Geophys. Res. Atmos., 118, 943-964, doi:10.1029/ 2012JD017774.

Sheridan, P. J., D. J. Delene, and J. A. Ogren (2001), Four years of continuous surface aerosol measurements from the department of energy's atmospheric radiation measurement program southern great plains cloud and radiation testbed site, J. Geophys. Res., 106, 20,735-20,747, doi:10.1029/2001JD000785.

Sherman, J. P., P. J. Sheridan, J. A. Ogren, E. Andrews, D. Hageman, L. Schmeisser, A. Jefferson, and S. Sharma (2015), A multi-year study of lower tropospheric aerosol variability and systematic relationships from four North American regions, Atmos. Chem. Phys., 15, $12,487-12,517$

Shindell, D., and G. Faluvegi (2009), Climate response to regional radiative forcing during the twentieth century, Nat. Geosci., 2, 294-300.

Shiraiwa, M., Y. Kondo, T. Iwamoto, and K. Kita (2010), Amplification of light absorption of black carbon by organic coating, Aerosol Sci. Tech., $44,46-54$.

Spackman, J. R., et al. (2010), Aircraft observations of enhancement and depletion of black carbon mass in the springtime Arctic, Atmos. Chem. Phys., 10, 9667-9680.

Verma, R. L., et al. (2011), Seasonal variations of the transport of black carbon and carbon monoxide from the Asian continent to the western Pacific in the boundary layer, J. Geophys. Res., 116, D21307, doi:10.1029/2011JD015830.

Warneke, C., et al. (2009), Biomass burning in Siberia and Kazakhstan as an important source for haze over the Alaskan Arctic in April 2008, Geophys. Res. Lett., 36, L02813, doi:10.1029/2008GL036194.

Warneke, C., et al. (2010), An important contribution to springtime Arctic aerosol from biomass burning in Russia, Geophys. Res. Lett., 37, L01801, doi:10.1029/2009GL041816. 